\title{
Seismic Performance of Steel Fiber Reinforced Concrete Beam-Column Joints under the Variation of Column Axial Load
}

\author{
Musitefa Adem Yimer ${ }^{1 *}$, Temesgen Wondimu Aure ${ }^{2 a}$ \\ ${ }^{1}$ Department of Civil Engineering, Samara University, Samara, Ethiopia \\ ${ }^{2}$ Department of Civil Engineering, Addis Ababa Science and Technology University, \\ Addis Ababa, Ethiopia
}

\begin{abstract}
This study presents a finite element investigation of steel fiber reinforced concrete beam-column joints under cyclic loading with the variation of axial load. The aim of the study is to investigate the influence of axial load variations on the seismic behavior of steel fiber-reinforced concrete (SFRC) beam-column joints. Nonlinear finite element analysis with a damaged plasticity model in ABAQUS/Standard is adopted. The finite element model is verified using experimental results conducted by other researchers. Six SFRC specimens with different column axial load ratios and a $2 \%$ volume fraction of steel fiber were simulated under reversed cyclic loading. The parameters investigated are maximum load-carrying capacity, stiffness degradation, energy dissipation and failure mode. The results indicated that an increase of column axial load has a valuable influence to delay the initiation of cracks and damage accumulation, slightly improvement of the joint stiffness and improves the energy dissipation of joints at the initial stage of loading. Moreover, when the axial load level increases up to $50 \%$ of the column capacity, no cracks observed in the joint area and no change in the maximum load-carrying capacity. However, when the axial load level of more than $50 \%$ of the column capacity, the cyclic stiffness decreased slightly due to the deterioration caused by crushing of concrete in column. Thus, the results revealed that the increase of column axial load improves the confinement of steel fiber reinforced concrete beam-column joints, however, a threshold limit could be required.
\end{abstract}

Keywords: Beam-column joints; Steel fiber-reinforced concrete; Cyclic loading; Axial load variation; Nonlinear finite element analysis

\section{INTRODUCTION}

Moment resisting reinforced concrete frames are assemblies of beams and columns connected by beam-column joints. These frames should be adequate ductility, strength, energy dissipation and stiffness to resist the seismic loading without collapse [1]. Several studies [2-7] have established that SFRC is capable of improving the seismic behavior of reinforced concrete structural members, such as shear walls, beam-column joints, and flexural members subjected to seismic loads. Based on earlier studies, the application of SFRC considerably improve the shear strength [8,9], the flexural strength and ductility [10-12] and fracture toughness [13] of the reinforced concrete members. The use of SFRC as a minimum shear reinforcement for beams has been permitted in ACI 318 [14] following the research study by Parra-Montesinos [15]. An experimental study of such joint behavior is not feasible to assess the effect of several parameters involved in joint behavior. Furthermore, because of the difficulties in integrating the compressive column axial loading in the experimental setup, it is common practice to assume the column axial load to be zero or constant in most of the researchs [16]. Nonlinear finite element analysis, however, can be viewed as one of a convenient and reliable solution to investigate such effects. In this study, the seismic behavior of SFRC beam-column joints under the variation of axial load is carried out using the finite element software ABAQUS/Standard. The finite element model is validated against existing SFRC beam-column joints tested by Choi and Bae [12]. After validation of the model, eight SFRC beam-column joint specimens under cyclic loading is investigated by varying the column axial load ratio.

\section{RESEARCH SIGNIFICANCE}

The use of steel fibers in RC members can offer a positive influence. However, due to the high expenses and restrictions of specimen fabrication, experimental tests for reinforced concrete structures need spending a great amount of time and money, especially countries not have advanced laboratories. Moreover, due to the complexity of incorporating the column axial load in the experimental test setup, it is common to assume the column axial load to be zero or constant in most of the investigations [16]. Hence, further study needs on SFRC beam-column joints with the variation of axial load. This study provides the finite element results on the seismic performance of SFRC beam-column joints with the variation of compressive column axial load.

\section{FINITE ELEMENT MODEL}

A three dimensional (3D) nonlinear finite element model of SFRC beam-column joints are developed using ABAQUS/Standard [17] by considering both geometric and material nonlinearities.

\subsection{Element types, meshes and boundary conditions}

A three-dimensional linear 8-node brick elements (C3D8R) were employed for modeling of steel fiber reinforced concrete and steel plate. Two-node linear three-dimensional truss elements (T3D2) was used to model steel reinforcements. A mesh size of 40 
$\mathrm{mm}$ is used for the whole geometry for all elements. To apply the boundary conditions identical to the reference experimental test setup, the nodes at the surfaces of the lower and upper column ends are attached to a reference point using the coupling constraint. The loading steel plate at the tip of the beam was constrained in y-direction for the cyclic loading application. The boundary conditions, mesh and were set in the model as shown in Fig. 1.

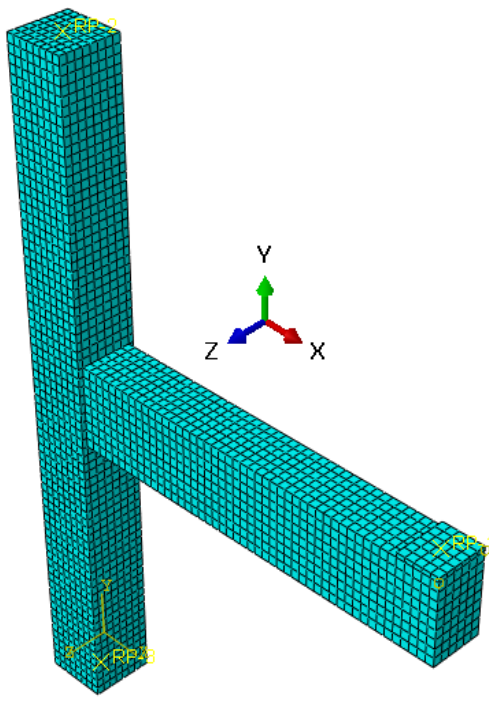

(a)

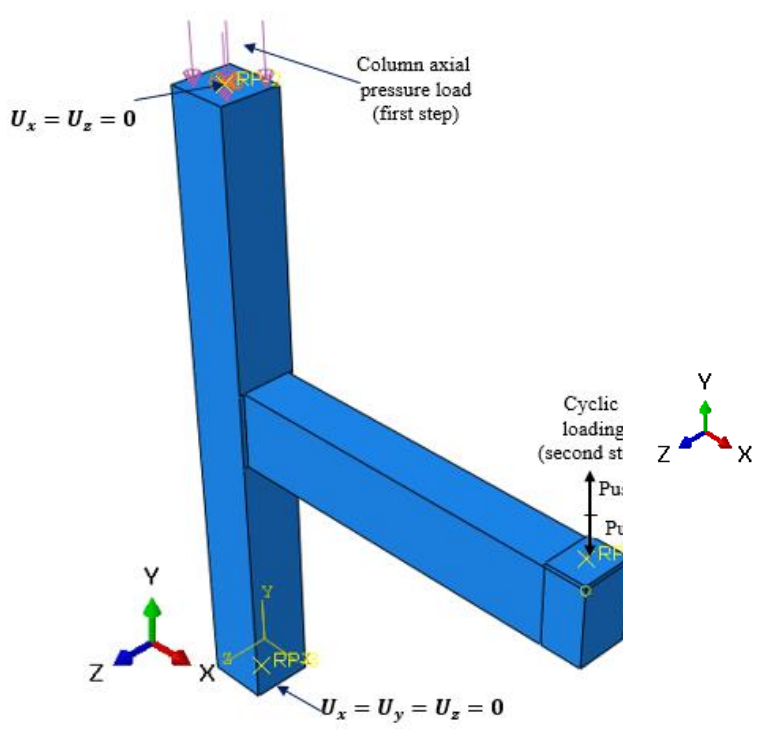

(b)

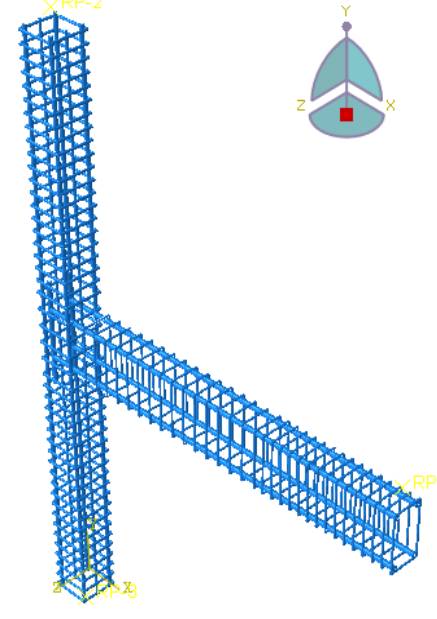

(c)

Fig. 1-Boundary conditions, meshing and loading of the FE model

\subsection{Interactions between Components}

The embedded approach was adopted for the interaction between the SFRC and the steel reinforcement, which enforces displacement continuity and the perfect bond between the two elements. The interaction between concrete and reinforcement after cracking was incorporated only in a simplified way using the tension stiffening in the concrete model. This was adopted to approximately simulate load transfer between cracks over the rebar [18,19]. The interactions between the surfaces of the inelastic and elastic solid bodies representing the concrete material and the loading steel plate is modelled using tie constraints.

\subsection{Load Application Method and Cyclic Loading Protocol}

In this study, the loading on the beam tip is adopted as in the experimental setup by Choi and Bae [12]. Additionally, the ACI 374 [20] recommendation for reverse cyclic loading protocol is used with the same loading history as reported in the experimental study, as showed in Fig. 2. The reversed cyclic load is applied in terms of displacement-controlled step, where the displacement is determined from the drift ratio $(\%)$ based on the following expression:

$$
\text { Drift ratio }(\%)=\frac{\Delta l}{l_{b}} \times 100
$$

Where $\Delta l$ and $l_{b}$ are the applied displacement at the beam tip and length of the beam from column face to the application point of the cyclic displacement, respectively. Analogous to the test loading condition, two loading steps are defined in the finite element modeling. The first step is the axial load step where the axial load is applied at the column top surface as a pressure load in a loadcontrolled mode and kept constant in the second step. Then, the reverse cyclic loading is applied in the second step on the beam end at a distance of $1800 \mathrm{~mm}$ from the beam-column interface. 


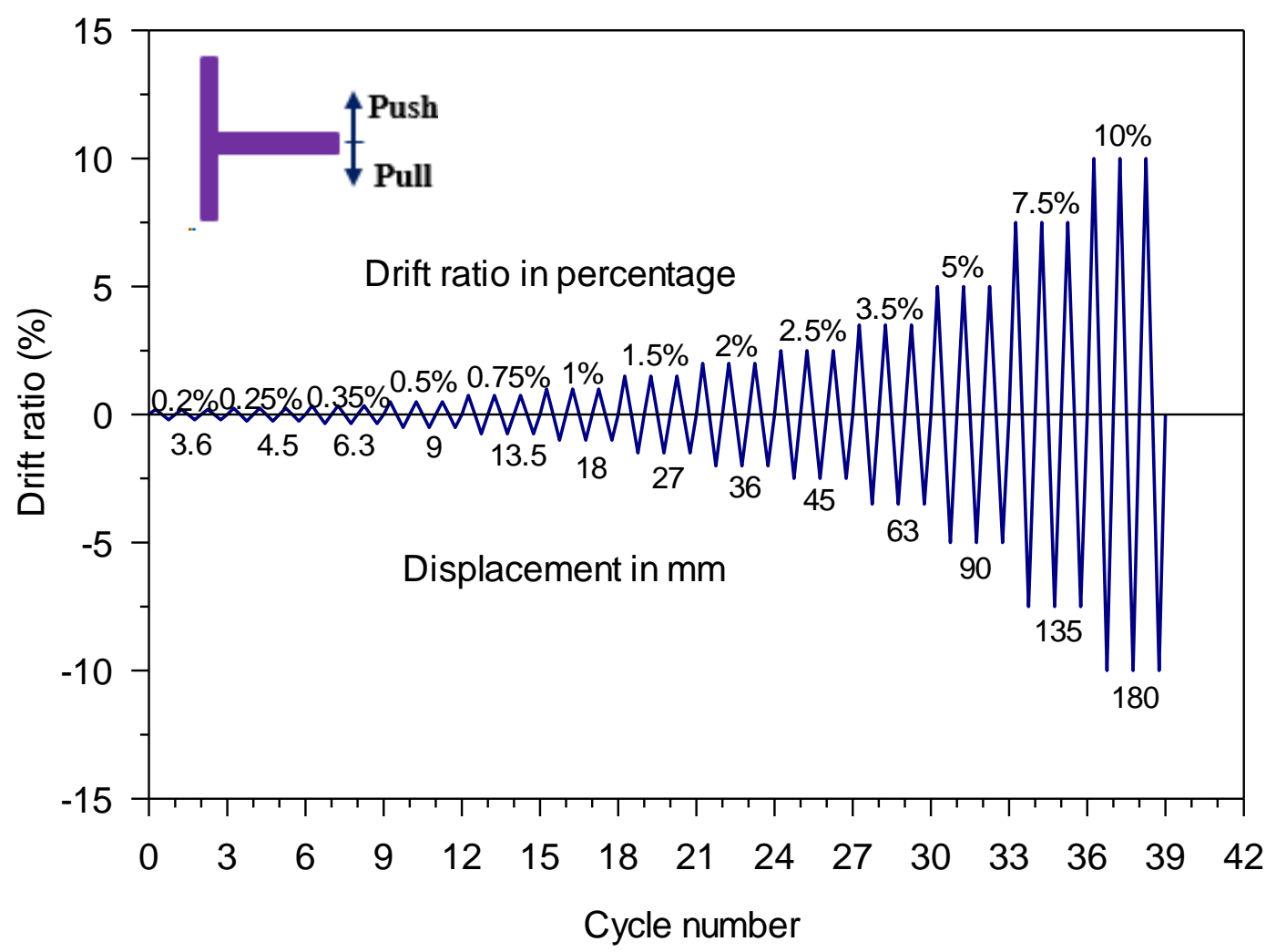

Fig. 2-Schematic representation of the loading history based on ACI 374 used by Choi and Bae [12].

\subsection{Analysis Approach}

Nonlinear finite element analysis of the beam-column joint specimens was performed in ABAQUS/standard by considering both geometric and nonlinearities with viscose regularization. In the static general analysis procedure of structural components, an appropriate solution algorithm is needed to solve the nonlinear equations. Newton-Raphson equilibrium iteration provides convergence at the end of each load increment within tolerance limits for all degree of freedoms in the model $[18,19]$. Automatic increment with a large number of increments and a small-time step size are used to improve the convergence rate.

\subsection{Material modeling}

The concrete damaged plasticity (CDP) model available in ABAQUS was adopted for the non-linear material behavior of steel fiber reinforced concrete in compression and cracking in tension. The CDP model uses the concepts of compressive crushing and tensile cracking to represent the inelastic behaviors of quasi-brittle material. The plasticity of the steel reinforcement and the elastic behavior of the steel plate were considered in the finite element modeling. The CDP model is effective for the analysis of concrete structures under monotonic, cyclic, and dynamic loading $[18,19,21]$. The CDP model was developed by Lubliner et al. [22] and later refined by Lee and Fenves [23]. In uniaxial compressive loading, the CDP model performs linearly up to the value of the initial yield is reached, then followed by a stress hardening and strain softening beyond the ultimate stress. After the calibration of the CDP model parameters on the experimental specimen, JNR-2-BTR, tested by Choi and Bae [12], the considered parameters in the CDP model for all specimens were presented in Table 1.

Table 1- The adopted input parameters in the CDP model

\begin{tabular}{|l|l|}
\hline Plasticity Parameters & Values \\
\hline Dilation Angle $(\psi)$ & $32^{\circ}$ (calibrated) \\
\hline Viscosity Parameter, $\mu$ & 0.0025 (calibrated) \\
\hline Shape factor $\left(K_{c}\right)$ & 0.8 (calibrated) \\
\hline Stress ratio $\left(\frac{\sigma_{b 0}}{\sigma_{c 0}}\right)$ & 1.16 (default value) \\
\hline Eccentricity $(\varepsilon)$ & \\
\hline
\end{tabular}


According to ACI 544.3R-93 [24] report, normal weight SFRC with a fiber content up to $2 \%$ by volume has a density in the same range as normal concrete of 2306 to $2403 \mathrm{~kg} / \mathrm{m}^{3}$. Also, according to the ACI 544.1R-96 [25] report, the density and Poisson's ratio of SFRC are generally taken as same range as to those of normal concrete when the volume percentage of steel fiber is up to $2 \%$. In this study, the Poisson's ratio and density were taken as 0.2 and $2400 \mathrm{~kg} / \mathrm{m}^{3}$, respectively, for steel fiber reinforced concrete material modeling based on the above recommendations.

\subsubsection{Modeling of SFRC in Compression}

Several investigators have proposed models for the characterization of the compressive stress-strain behavior of SFRC [26-31] all have relatively similar approximations of the SFRC behavior under uniaxial compression. Generally, steel fibers only have minor effects on the ultimate compressive strength of concrete, slightly increasing or decreasing its magnitude, depending on the characteristics of the fibers [25,32]. However, the use of steel fiber in concrete significantly enhances the descending branch of the compressive stress-strain curve. Due to this, a compressive constructive model of SFRC differs other than normal concrete compressive model was still employed. In this study an attempt was made in the validation section from different SFRC compressive stress-strain model and the model proposed by Lee et al. [31] was adopted. Based on this constitutive model, the behavior of the SFRC was assumed to be elastic linear up to reaching $0.4 f_{c s}^{\prime}$. After this point, the plastic behavior was defined using the following equations.

$$
\begin{aligned}
& f_{c S}=f_{c S}^{\prime}\left[\frac{A\left(\varepsilon_{c S} / \varepsilon_{0}\right)}{A-1+\left(\varepsilon_{c s} / \varepsilon_{0}\right)^{B}}\right] \\
& \text { Where; for pre-peak: } A=B=\frac{1}{1-\left(\frac{f_{c s}^{\prime}}{\varepsilon_{0} E_{c s}}\right)} \text { for } \varepsilon_{c s} / \varepsilon_{0} \leq 1.0 \\
& \text { For post-peak: } B=\left(\frac{f_{c S}^{\prime}}{\varepsilon_{0} E_{c s}}\right)^{0.064}\left[1+0.882\left(V_{f} \frac{l_{f}}{d_{f}}\right)^{-0.882}\right] \geq A \\
& A=1+0.723\left(V_{f} \frac{l_{f}}{d_{f}}\right)^{-0.957} \text { for } \varepsilon_{c s} / \varepsilon_{0}>1.0 \\
& \text { Where; } \varepsilon_{0}=\left(0.0003 V_{f} \frac{l_{f}}{d_{f}}+0.0018\right) f_{c S}^{0.12} \\
& E_{c S}=\left(-367 V_{f} \frac{l_{f}}{d_{f}}+5520\right) f_{c S}^{\prime 0.41}
\end{aligned}
$$

Where $f_{c S}$ is the uniaxial compressive stress of SFRC, $f_{c S}^{\prime}$ is compressive strength of SFRC, $E_{c s}$ is the initial elastic modulus of $\mathrm{SFRC}, \varepsilon_{c s}$ is the uniaxial compressive strain of SFRC, $\varepsilon_{0}$ is strain of SFRC at peak stress, $V_{f}$ is the volume fraction of steel fiber, $l_{f}$ is length steel fiber and $d_{f}$ is the diameter of steel fiber. As mentioned in previous section, hooked steel fiber with a length of $30 \mathrm{~mm}$ and a diameter of $0.5 \mathrm{~mm}$ was used in this study for consistency of the referenced experimental study by Choi and Bae [12]. Equation (8) which is proposed by Ou et al. [33] was used to estimate the compressive strength of SFRC because it gives an approximately equal value with the referenced experimental test data reported by [12].

$$
f_{c S}^{\prime}=f_{c}^{\prime}+2.35 R I
$$

Where, $f_{c}^{\prime}$ is the compressive strength of normal concrete; $f_{c S}^{\prime}$ is compressive strength of SFRC and $R I$ is the fiber reinforcing index which expressed as:

$$
R I=V_{f} \frac{l_{f}}{d_{f}}
$$

The ultimate strain for SFRC was set to the value $\varepsilon_{u}=0.02$ according to the work reported by Wang [34] for $V_{f}>0.5 \%$.

\subsubsection{Modeling of SFRC in Tension}

There are a number of different constitutive models developed by researchers to represent the tensile behavior of SFRC [27,3537]. In this study, the model proposed by Lok and Xiao [36] was employed to represent the tensile behavior of SFRC. Furthermore, a number of researchers [38,39] conducted a non-linear finite element analysis of fiber reinforced concrete elements by using this model and found the Lok and Xiao [36] for SFRC material behavior in tension resulted in precise predictions. The uniaxial tensile stress-strain relationships of SFRC by Lok and Xiao [36] model shown in Fig.3 and which expressed by Eqs. (10)-(11):

$$
\begin{array}{ll}
\sigma=f_{t}\left[2\left(\frac{\varepsilon}{\varepsilon_{t 0}}\right)-\left(\frac{\varepsilon}{\varepsilon_{t 0}}\right)^{2}\right] & \text { for } 0 \leq \varepsilon \leq \varepsilon_{t 0} \\
\sigma=f_{t}\left[1-\left(1-\frac{f_{t u}}{f_{t}}\right)\left(\frac{\varepsilon-\varepsilon_{t 0}}{\varepsilon_{t 1}-\varepsilon_{t 0}}\right)\right] & \text { for } \varepsilon_{t 0} \leq \varepsilon \leq \varepsilon_{t 1} \\
\sigma=f_{t u} & \text { for } \quad \varepsilon_{t 0} \leq \varepsilon \leq \varepsilon_{t u}
\end{array}
$$

Where; $f_{t}$ is the ultimate uniaxial tensile strength of SFRC, $\varepsilon_{t 0}$ is the corresponding ultimate tensile strain, $f_{t u}$ is the residual strength from the strain, $\varepsilon_{t 1}$, as shown in Fig. 3. These values are defined by [40] as follows:

$$
\begin{gathered}
f_{t u}=\eta v_{f} \tau_{d} \frac{l_{f}}{d_{f}} \\
\varepsilon_{t 1}=\tau_{d} \frac{l_{f}}{d_{f}} \frac{1}{E_{s f}}
\end{gathered}
$$


Where $\eta$ is the fiber orientation factor in a three dimensional (3D) case. Hannant [41] used the value of $\eta$ as 0.50 , Soroushian and Lee [42] taken as 0.405 and Lok and Xiao [36] taken as 0.50 for slabs and 0.405 for beams. In the present work, $\eta$ is taken as 0.50. The value of modulus elasticity of steel fiber $\left(E_{s f}\right) 200 \mathrm{GPa}$ used in this study recommended by Amin and Gilbert [43]. According to Lok and Xiao [40], the initial tangent modulus of SFRC in tension and in compression is assumed to be equal, and the ultimate tensile strain $\varepsilon_{t 0}$, corresponding to $f_{t}$ expressed as:

$$
\varepsilon_{t 0}=\frac{2 f_{t}}{E_{t 0}}
$$

where, $E_{t 0}$ is the initial tangent modulus of steel fiber reinforced concrete.

For hooked-type steel fibers, the value of bond stress $\left(\tau_{d}\right) 6.8 \mathrm{MPa}$ is used in this study as suggested by Lim et al [44]. Equation (16) which is the correlation between splitting tensile strength $\left(f_{s p t}\right)$ and compressive strength $\left(f_{c s}\right)$ of SFRC proposed by [45] was used to estimate the splitting tensile strength $\left(f_{\text {spt }}\right)$ of SFRC:

$$
f_{\text {spt }}=0.21\left(f_{c s}\right)^{0.83}
$$

However, the CDP model requires the uniaxial tensile strength as an input. Therefore, the relation is given in Eq. (17) based on Eurocode 2 [46] recommendation was used to convert the splitting tensile strength into a uniaxial one.

$$
f_{c t}=0.9 f_{s p t}
$$

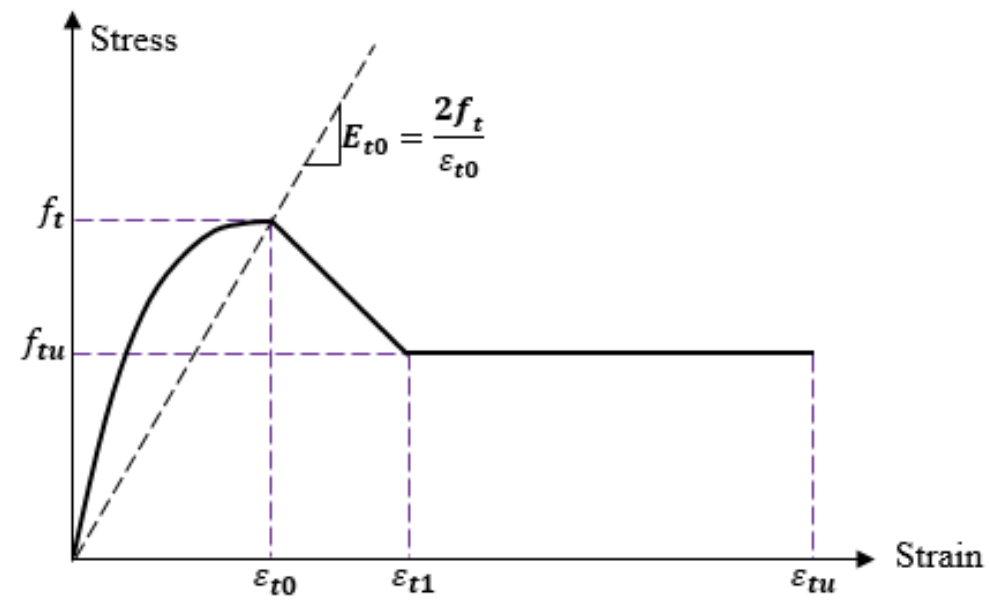

Fig. 3-Tensile stress-strain behavior of SFRC used in FE model by Lok and Xiao [36].

\subsubsection{Steel Reinforcement and Steel Plate Modelling}

The mechanical properties of reinforcing bars were employed to represent the longitudinal reinforcement and shear stirrups in numerical modeling were exactly the same as the material properties reported by Choi and Bae [12] as presented in Table 2 and Poisson's ratio of 0.3 .

Table 2- Mechanical properties of reinforcing bars used by Choi and Bae [12].

\begin{tabular}{|c|c|c|c|c|}
\hline Bar ID & $f_{y}(M P a)$ & $f_{y m}(M P a)$ & $\varepsilon_{y}(m m / m m)$ & $f_{u}(M P a)$ \\
& & & & \\
\hline D10 & 400 & 436.9 & 0.0022 & 517.0 \\
\hline D13 & 400 & 400.0 & 0.0020 & 472.3 \\
\hline D13 & 500 & 505.8 & 0.0025 & 521.8 \\
\hline D19 & 500 & 558.7 & 0.0028 & 656.1 \\
\hline D25 & 400 & 471.7 & 0.0024 & 587.6 \\
\hline
\end{tabular}

Note: $f_{y}$ is specified minimum yield strength, $f_{y m}$ is measured yield strength, $\varepsilon_{y}$ is yield strain, and $f_{u}$ is ultimate tensile stress. The tensile stress-strain of reinforcing bars was assumed to be elastic with corresponding Young's modulus and Poisson's ratio. The nonlinear behavior of steel bars was modeled as a bilinear elastic-plastic material using a strain hardening ratio of 0.01 , as recommended by Kachlakev and Miller [47] and it is used by many researchers [48,49]. The typical bilinear stress-strain model of reinforcement bars is shown in Fig. 4. In order to avoid the concentration of stresses on the concrete, premature failure or cracking at the cyclic loading point a $20 \mathrm{~mm}$ thick steel plates were used at this loading point. This loading steel plate is modeled with elastic properties steel material having an elastic modulus $\left(\mathrm{E}_{\mathrm{s}}\right)$ of $200 \mathrm{GPa}$, Poisson's ratio of 0.3 , and no yielding strength to avoid any premature failure in the steel plates. 


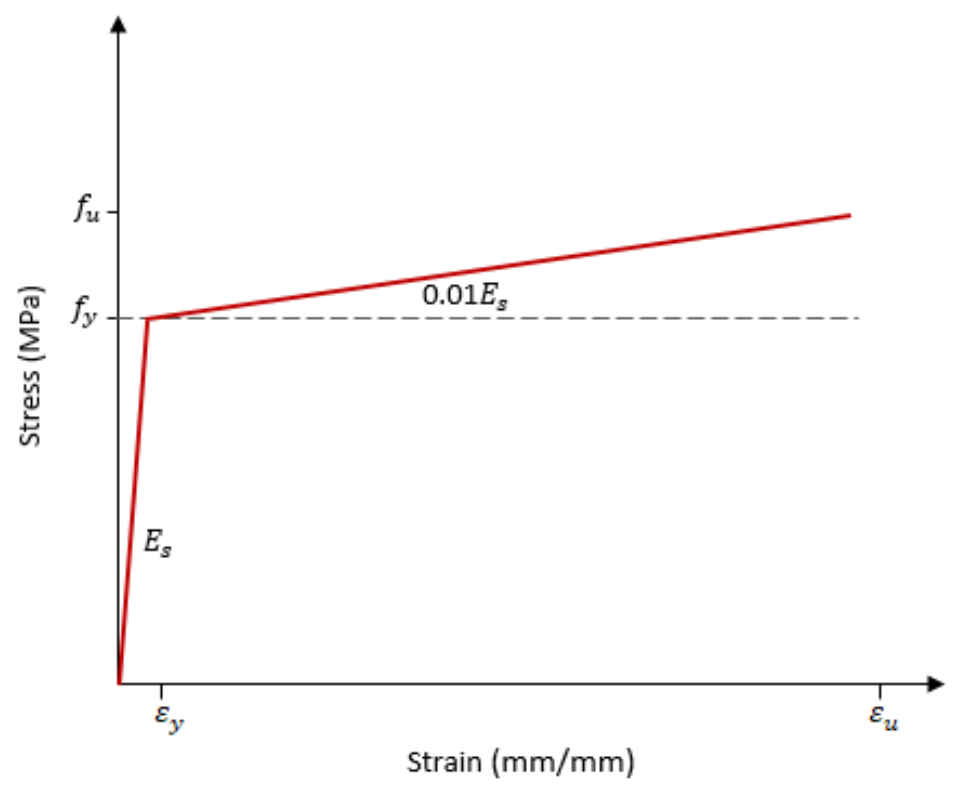

Fig. 4- Bilinear stress-strain model for reinforcing steel bars by Kachlakev and Miller [47].

\section{MODEL VALIDATION}

Existing steel fiber reinforced concrete beam-column joint specimen which experimentally tested by other researchers was used for model validation.

\subsection{Details of experimental specimen used for validation}

To investigate the behavior of SFRC beam-column joints numerically, the performance of the nonlinear finite element models developed in this paper are validated against experimental specimen tested by Choi and Bae [12], namely JNR-2-BTR was selected. According to their study, the specimen represented the first-floor exterior beam-column joint (at a scale of two-third) subassemblies of a 10-story office building. The specimen, JNR-2-BTR, is designed without any hoops in the joint panel region and made with a $2 \%$ volume fraction of steel fiber in concrete, but the beam and column are reinforced by hoops based on ACIASCE Committee 352 [50]. Hooked steel fiber with a length of $30 \mathrm{~mm}$ and a diameter of $0.5 \mathrm{~mm}$ was used in the experimental study in consistence with ACI 318 [51] as shown in Fig. 5. The columns had a cross-section of $300 \mathrm{~mm} \times 300 \mathrm{~mm}$, with a height of $3000 \mathrm{~mm}$. The beam had a cross-sectional dimension of $250 \mathrm{~mm} \times 375 \mathrm{~mm}$ with lengths of $1900 \mathrm{~mm}$ up to the contra-flexure point in all sub-assemblages. The reinforcement details and geometry of the validated specimen is displayed in Fig. 6.
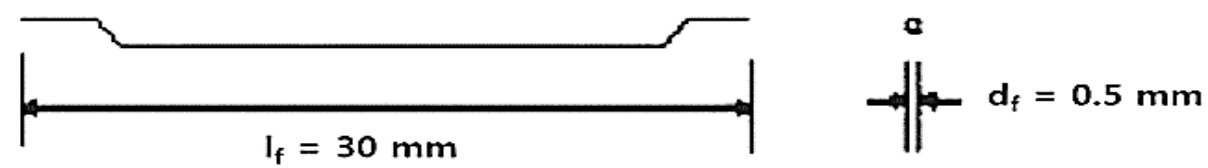

Fig. 5-Size and shape of steel fiber used in an experimental study by Choi and Bae [12]. 


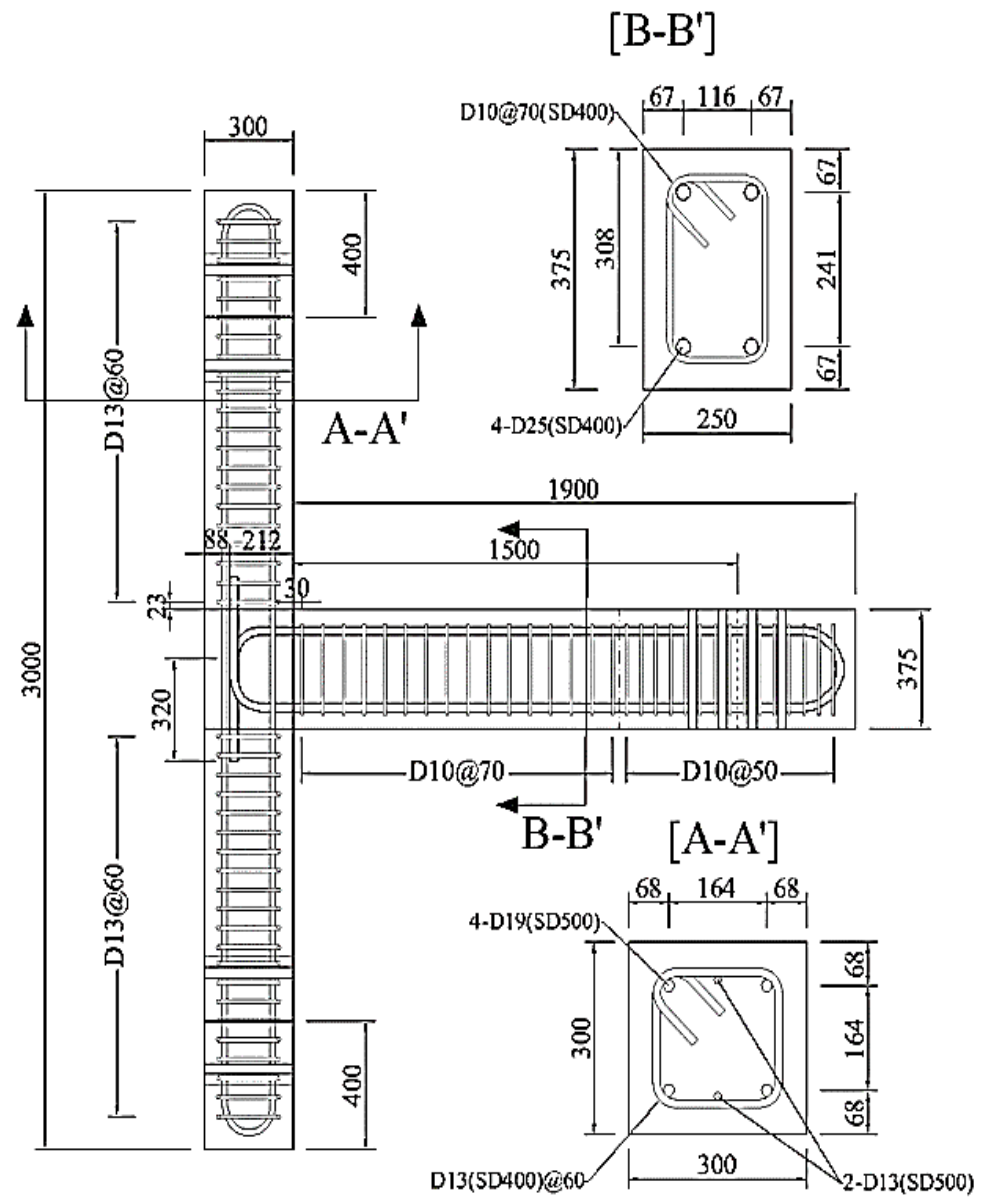

Fig. 6-Details of the specimen JNR-2-BTR tested by Choi and Bae [12].

Furthermore, the geometrical properties, variables and details as presented in Table 3. The compressive and indirect splitting tensile strength for the SFRC reported in the experimental study are presented in Table 4. In experimental study, beam-column joint specimens were loaded using a hydraulic actuator under cyclic loading applied tip of the beam as a displacement controlled. The axial load was applied on the top of the column.

Table 3-Cross-sections, variables and details of specimens tested by Choi and Bae [12].

\begin{tabular}{|c|c|c|c|c|c|c|c|c|}
\hline \multirow[t]{3}{*}{ Specimen } & \multirow{3}{*}{$\frac{P}{f_{c s}{ }^{\prime} A_{g}}$} & \multicolumn{3}{|l|}{ Beam } & \multicolumn{3}{|l|}{ Column } & \multirow{3}{*}{$V_{f}(\%)$} \\
\hline & & $\begin{array}{l}\text { Cross-section } \\
(\mathrm{mm})\end{array}$ & $\begin{array}{l}\text { Bars (mm) } \\
\text { (top \& }\end{array}$ & $\begin{array}{l}\text { Stirrups } \\
(\mathrm{mm})\end{array}$ & $\begin{array}{c}\text { Cross- } \\
\text { section }(\mathrm{mm})\end{array}$ & Bars & $\begin{array}{l}\text { Stirrups } \\
(\mathrm{mm})\end{array}$ & \\
\hline & & $b_{b} \times h_{b}$ & botton & & $b_{c} \times h_{c}$ & & & \\
\hline JNR-2-BTR & 0.1 & $250 \times 375$ & $4 \mathrm{D} 25$ & $\begin{array}{l}\text { D10@70 } \\
\end{array}$ & $300 \times 300$ & 4D19+2D13 & D13@60 & 2 \\
\hline
\end{tabular}

Note: $\mathrm{P}$ is the applied axial load to column, $f_{c s}{ }^{\prime}$ is the cylindrical compressive strength of the concrete steel fiber concrete, $A_{g}$ is the area of the column, $D$ is the diameter of reinforcement bar; $b_{b}$ is width of beam, $h_{b}$ is overall depth of beam, $b_{c}$ is width of column, $h_{c}$ is overall depth of column, and $V_{f}$ is volume fraction of steel fiber. (Note: $1 \mathrm{~mm}=0.0394 \mathrm{in}$.)

Table 4-Mechanical properties of concrete tested by Choi and Bae [12]

\begin{tabular}{|c|c|c|c|c|}
\hline Concrete ID & $V_{f}(\%)$ & $E_{c s}(M P a)$ & $f_{c s}{ }^{\prime}(M P a)$ & $f_{s p}(M P a)$ \\
& 2 & 31826 & 54.7 & 6.5 \\
\hline SFRC2 & 2 & & \\
\hline
\end{tabular}

Note: $V_{f}$ is volume fraction of steel fiber, $E_{c S}$ is the modulus of elasticity of SFRC, $f_{c s}{ }^{\prime}$ is compressive strength of cylinder and $f_{s p}$ is splitting tensile strength of SFRC.

\subsection{Finite element model predictions}

As described before in the summary of experimental work the specimen, JNR-2-BTR, which were experimentally tested by Choi and Bae [12], was selected to validate the developed finite element model. The accuracy of the nonlinear finite element model 
was evaluated by comparing the nonlinear finite element analysis (NLFEA) results of this specimens with experimental result in terms of load-displacement response and failure pattern.

\subsubsection{Load-Displacement Response}

The load-displacement envelope curves obtained from nonlinear finite element analysis compared with the experimental results of the specimen JNR-2-BTR are displayed in Fig. 7 (a-b). The higher stiffness in finite element models may result from more micro-cracks reducing the stiffness of the experimental test. It is obvious that more micro-cracks are presents in test, while finite element models do not include these micro-cracks [52]. The load-displacement curve predicted by the NLFEA shows a very good agreement with that of the experimental result. The average maximum load obtained from the NLFEA analysis was 3.35\% lower than the average maximum load reported from the experimental study (refer Table 5 for comparison).

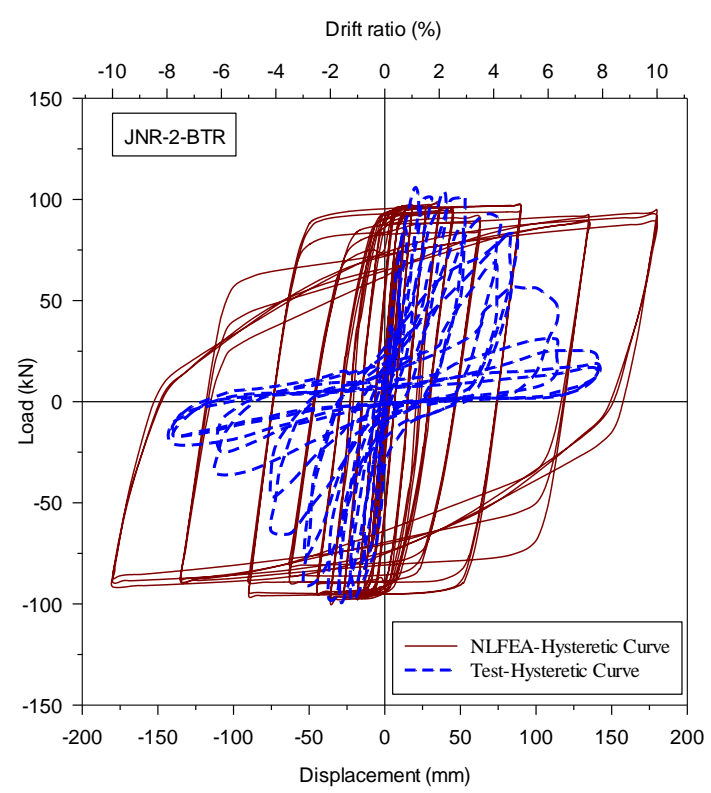

(a) Hysteretic curves

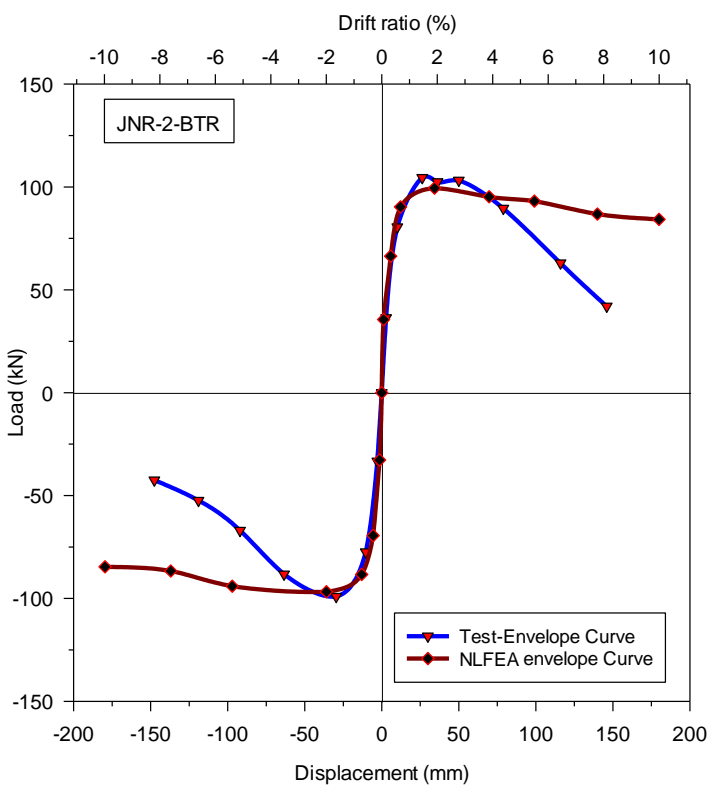

(b) Envelope curves

Fig. 7-Load-displacement hysteretic and envelope curves of JNR-2-BTR [12]

From the above figures, the ABAQUS models show the envelope curve precisely. However, the hysteretic loops of the ABAQUS models as compared to the test results are exhibit a fat-pinching distance as expected from the embedded method of concrete and reinforcement modeling. This pinching distance clearly described that the tension stiffening approximate consideration of bondslip effect in the modelling due to the adoption of the embedded (perfect bond) method to simulate the bond between reinforcements and concrete.

The error and overall model accuracy predicted by NLFEA is compared with the test result and presented in Table 5. In order to express the overall model accuracy, and accompanying average underestimation or overestimation of the NLFEA, the error (\%) and mean model accuracy [M (\%)] estimated based on the relation given in (Behnam et a., 2018) and it defined as:

$$
\begin{aligned}
& \text { Error }(\%)=\left|\frac{N L F E A \text { result }- \text { Test result }}{\text { Test result }}\right| \times 100 \\
& \text { Mean model accuracy, } M(\%)=\frac{\text { NLFEA result }}{\text { Test result }} \times 100
\end{aligned}
$$

It can be seen in Table 5 that in all cases, the model prediction of the joint diagonal cracking load and maximum load lead to an error below 5\%, which once again shows that the nonlinear finite element simulated response of the specimens was in a very good agreement with the results reported from the experimental study.

Table 5- Diagonal cracking load and maximum load comparisons of NLFEA prediction with the experimental results of the two specimens.

\begin{tabular}{|c|c|c|c|c|c|c|c|c|}
\hline \multirow[t]{2}{*}{ Specimen } & \multicolumn{2}{|c|}{$\begin{array}{l}\text { Average load at joint } \\
\text { diagonal cracking }(\mathrm{kN})\end{array}$} & \multicolumn{2}{|c|}{ Prediction } & \multicolumn{2}{|c|}{ Average maximum Load $(\mathrm{kN})$} & \multicolumn{2}{|c|}{ Prediction } \\
\hline & NLFEA & Test & Error $(\%)$ & $\mathrm{M}(\%)$ & NLFEA & Test & Error $(\%)$ & $\mathrm{M}(\%)$ \\
\hline JNR-2-BTR & 85.31 & 88.21 & -3.29 & 96.71 & 99.73 & 103.19 & -3.35 & 96.65 \\
\hline
\end{tabular}

\subsubsection{Failure Pattern}

Fig. 8 and Fig. 9 shows the comparison of crack patterns in specimens JNR-2-BTR obtained by the nonlinear finite element simulation and reported from the experimental study at the maximum load and at failure load stage, respectively. These responses 
clearly demonstrate that there is a very good agreement between the experimental and nonlinear finite element prediction crack patterns. This numerical result also further approves the accuracy of the nonlinear finite element model and shows strong capability in predicting the general behavior of both the reinforced concrete and steel fiber reinforced concrete specimens. Therefore, the model can be used as an effective and reliable numerical tool for further studies on SFRC beam-column joints. Based on the comparisons, it can be concluded that the developed finite element model can successfully predict the seismic behavior of SFRC beam-column joints with high accuracy.

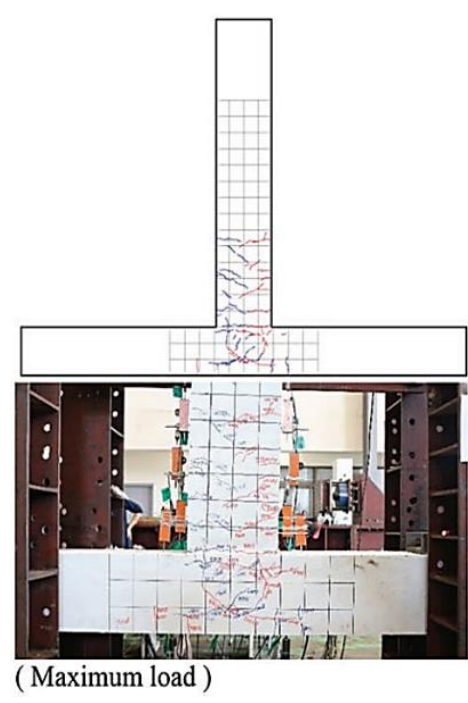

(a) Experimental

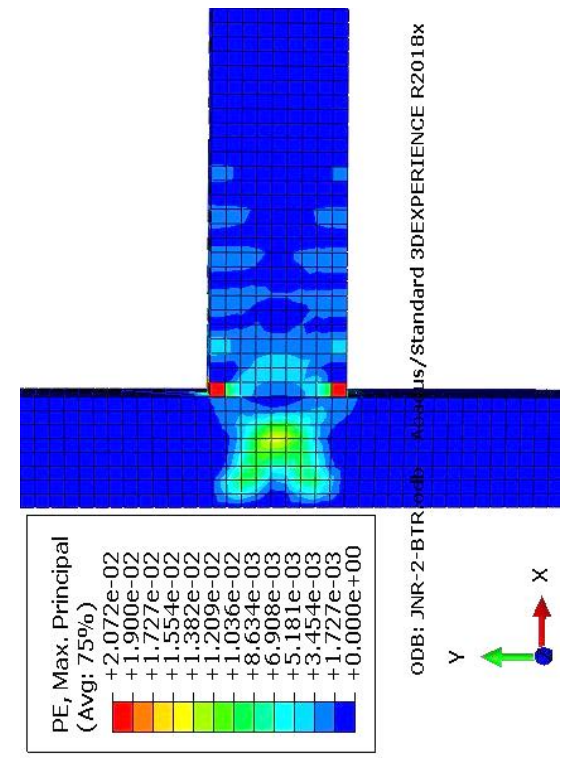

(b) NLFEA (ABAQUS) Fig.8-Comparison of crack patterns at maximum load stage of JNR-2-BTR [12].

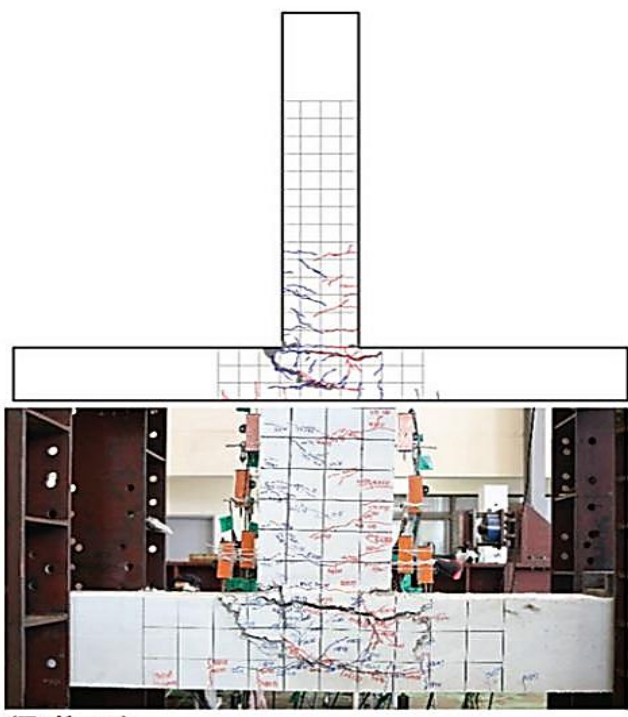

(Failure)

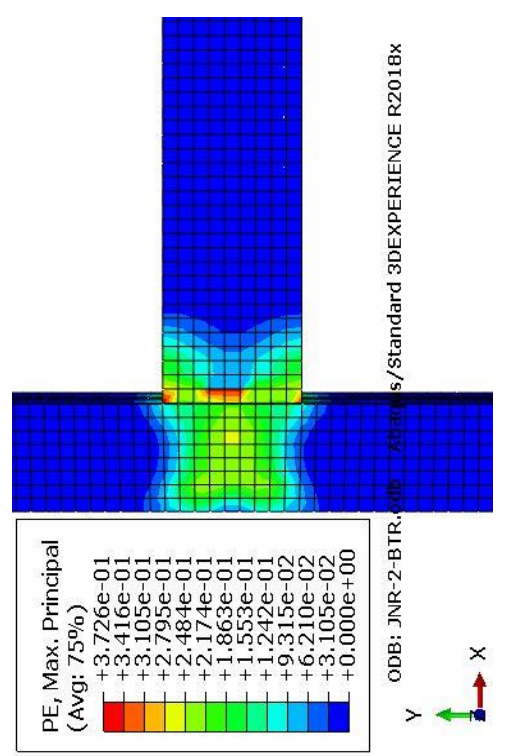

(b) NLFEA (ABAQUS)

(a) Experimental

ecimen JNR-2-BTR [12]. 


\subsection{Specimens description}

\section{PARAMETRIC STUDY}

The level of axial load is described as a percentage of $\left(f_{c s}^{\prime} A_{g}\right)$, where $\left(A_{g}\right)$ is the area of column cross-section and $\left(f_{c s}^{\prime}\right)$ is compressive strength of steel fiber reinforced concrete having $2 \%$ volume faction of steel fiber. The column axial load is applied as pressure compressive stress. Eight different column compressive axial load levels: (0.0, 0.05, 0.1, 0.2, 0.3, 0.5, 0.7 and 0.75) $\times\left(f_{c S}^{\prime} A_{g}\right)$; were modeled and simulated. Based on the amount of axial load ratio, these eight specimens designated as JS4-SFRC2A0, JS4-SFRC2-A05, JS4-SFRC2-A10, JS4-SFRC2-A20, JS4-SFRC2-A30, JS4-SFRC2-A50, JS4-SFRC2-A70 and JS4-SFRC2A75, respectively. The column and beam cross-section, length and reinforcement details are identical to the validated specimen (JNR-2-BTR) except the number of stirrups in joints panel zone. The joint reinforcement details of the parametric study specimens are as shown in Fig. 10. The description of the specimens with axial load variations are reported in Table 6.

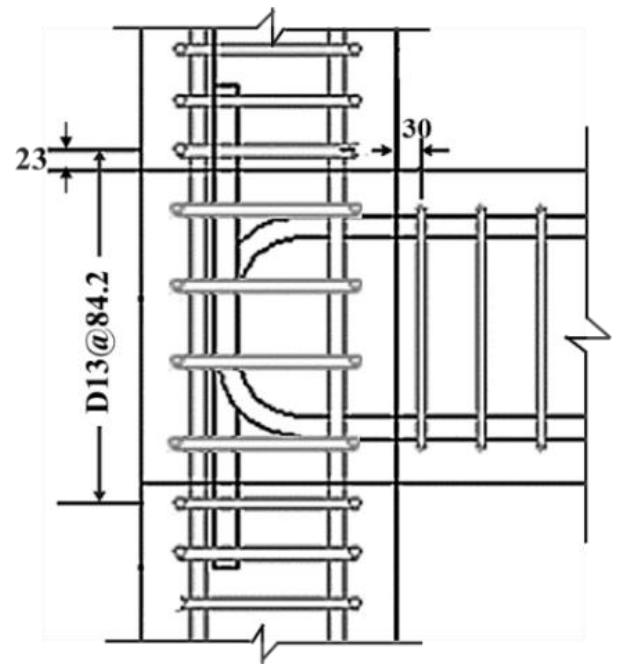

Fig. 10: Joint reinforcement details of all specimens. (Note: Dimensions in mm).

Table 6: Variables and details of specimens used in this study.

\begin{tabular}{|c|c|c|c|c|c|c|c|c|c|}
\hline \multirow[b]{2}{*}{ Specimen } & \multirow[b]{2}{*}{$\frac{P}{f_{c}^{\prime} A_{g}}$} & \multicolumn{3}{|c|}{ Beam } & \multicolumn{3}{|c|}{ Colvmn } & \multirow{2}{*}{$\begin{array}{l}\text { Joint } \\
\text { Stirrups } \\
(\mathrm{mm})\end{array}$} & \multirow[b]{2}{*}{$V_{f}(\%)$} \\
\hline & & $\begin{array}{r}\begin{array}{r}\text { Cross-section } \\
(\mathrm{mm} \times \mathrm{mm})\end{array} \\
b_{b} \times h_{b}\end{array}$ & $\begin{array}{c}\text { Bars (mm) } \\
\text { (top and } \\
\text { bottom) }\end{array}$ & $\begin{array}{c}\text { Stirrups } \\
(\mathrm{mm})\end{array}$ & $\begin{array}{c}\begin{array}{c}\text { Cross-section } \\
(\mathrm{mm} \times \mathrm{mm})\end{array} \\
b_{c} \times h_{c}\end{array}$ & $\begin{array}{c}\text { Bars } \\
(\mathrm{mm})\end{array}$ & $\begin{array}{c}\text { Stirrups } \\
(\mathrm{mm})\end{array}$ & & \\
\hline JS4-SFRC2-AO & 0 & $250 \times 375$ & $4 \mathrm{D} 25$ & D10@70 & $300 \times 300$ & $4 \mathrm{D} 19+2 \mathrm{D} 13$ & D13@60 & $4 \mathrm{D} 13 @ 84.2$ & 2 \\
\hline JS4-SFRC2-A05 & 0.05 & $250 \times 375$ & $4 \mathrm{D} 25$ & D10@70 & $300 \times 300$ & 4D19+2D13 & D13@60 & 4D13@84.2 & 2 \\
\hline JS4-SFRC2-A10 & 0.1 & $250 \times 375$ & $4 \mathrm{D} 25$ & D10@70 & $300 \times 300$ & $4 \mathrm{D} 19+2 \mathrm{D} 13$ & D13@60 & 4D13@84.2 & 2 \\
\hline JS4-SFRC2-A2O & 0.2 & $250 \times 375$ & $4 \mathrm{D} 25$ & D10@70 & $300 \times 300$ & $4 \mathrm{D} 19+2 \mathrm{D} 13$ & D13@60 & 4D13@84.2 & 2 \\
\hline JS4-SFRC2-A30 & 0.3 & $250 \times 375$ & $4 \mathrm{D} 25$ & D10@70 & $300 \times 300$ & $4 \mathrm{D} 19+2 \mathrm{D} 13$ & D13@60 & 4D13@84.2 & 2 \\
\hline JS4-SFRC2-A50 & 0.5 & $250 \times 375$ & $4 \mathrm{D} 25$ & D10@70 & $300 \times 300$ & $4 \mathrm{D} 19+2 \mathrm{D} 13$ & D13@60 & 4D13@84.2 & 2 \\
\hline JS4-SFRC2-A70 & 0.7 & $250 \times 375$ & $4 \mathrm{D} 25$ & D10@70 & $300 \times 300$ & $4 \mathrm{D} 19+2 \mathrm{D} 13$ & D13@60 & 4D13@84.2 & 2 \\
\hline JS4-SFRC2-A75 & 0.75 & $250 \times 375$ & $4 \mathrm{D} 25$ & D10@70 & $300 \times 300$ & 4D19+2D13 & D13@60 & $4 \mathrm{D} 13 @ 84.2$ & 2 \\
\hline
\end{tabular}

Note: $\mathrm{P}$ is the applied axial load to column, $f_{c}{ }^{\prime}$ is the compressive strength steel fiber reinforced concrete, $A_{g}$ is the area of column, $D$ is diameter of reinforcement bar; $b_{b}$ is width of beam, $h_{b}$ is overall depth of beam, $b_{c}$ is width of column, $h_{c}$ is overall depth of column, and $V_{f}$ is volume fraction of steel fiber.

\section{RESULTS AND DISCUSSIONS OF THE PARAMETRIC STUDY}

The main parameters investigated in this study due to the effects of axial load variation on the joint seismic behavior are loadcarrying capacity, crack patterns, energy dissipation, and stiffness degradation responses under cyclic loading. 


\subsection{Effects of Column Axial Load on Load-Carrying Capacity}

The hysteretic loops obtained from the nonlinear finite element simulation of specimens with different column axial load ratio are shown in Fig. 11 (a-h). The increasing of column axial load level from $0 \%$ to $20 \%$ of column capacity resulted in an increase of some extent (approximately 1.3\%) of the peak load-carrying capacity of the specimens. However, when the axial load level of more than $20 \%$ of the column capacity, the lateral strength deteriorate slightly due the development of greater compressive shear stress in the joint area. As displayed in Fig.13, the specimens with column axial loads exhibited early strength than the specimen simulated without axial load. The specimen which has not column axial load (JS4-SFRC2-A0) recorded its average maximum load-carrying load-capacity of $103.46 \mathrm{kN}$. The specimens JS4-SFRC2-A05, JS4-SFRC2-A10, JS4-SFRC2-A20, JS4-SFRC2A30, JS4-SFRC2-A50, JS4-SFRC2-A70 and JS4-SFRC2-A75, are exhibited their average maximum load of 103.59, 103.95, $104.79,104.23,104.38,104.35$ and $104.74 \mathrm{kN}$, respectively.

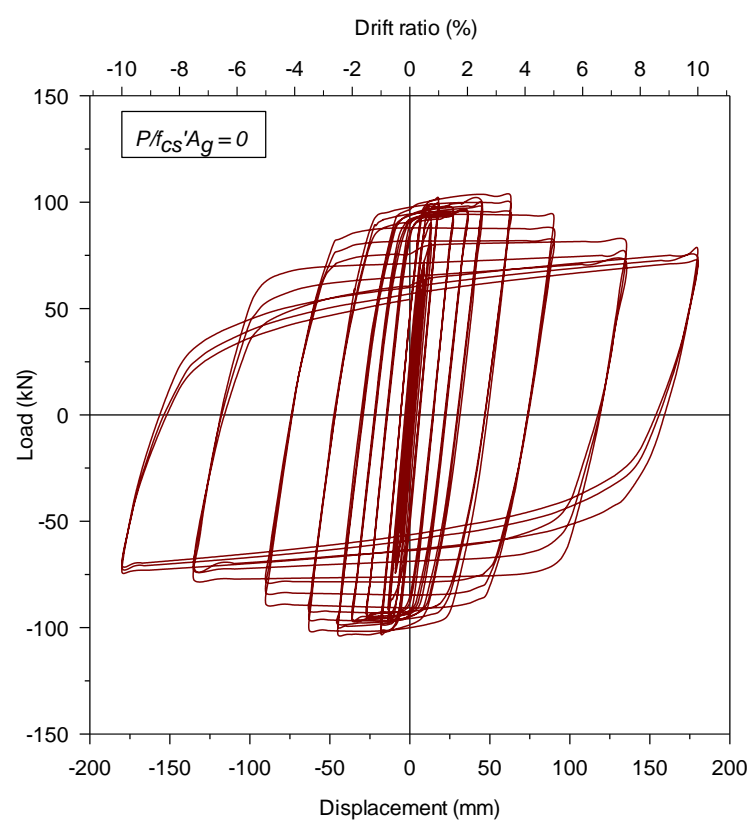

(a) JS4-SFRC2-A0

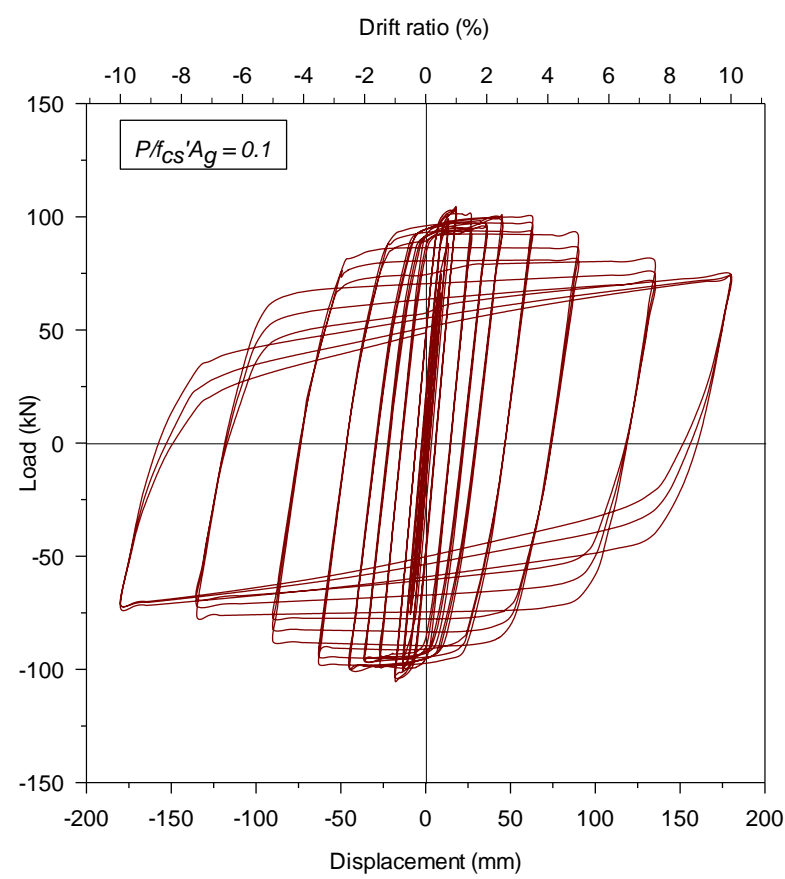

(c) JS4-SFRC2-A10

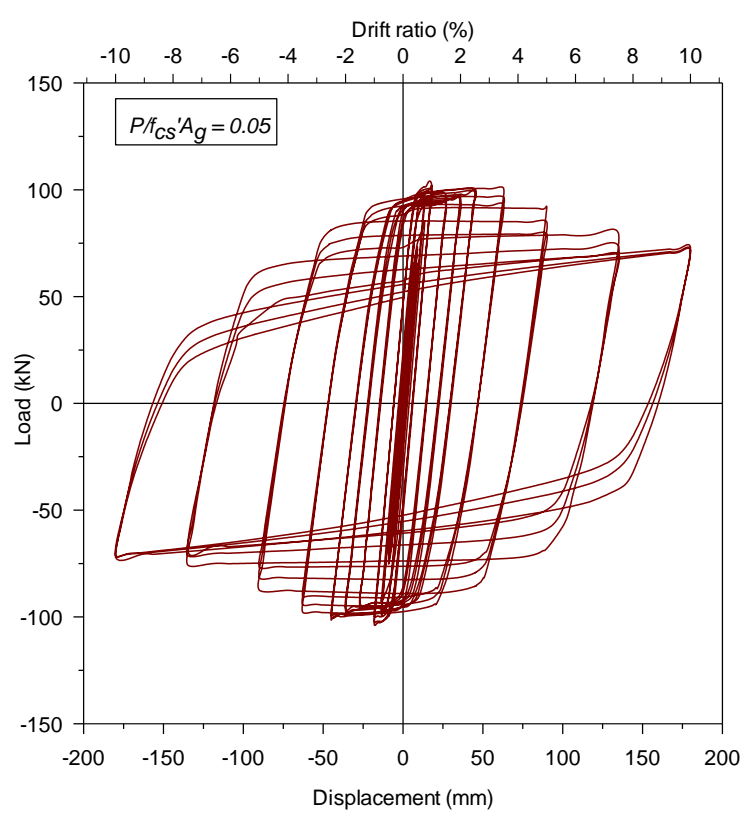

(b) JS4-SFRC2-A05

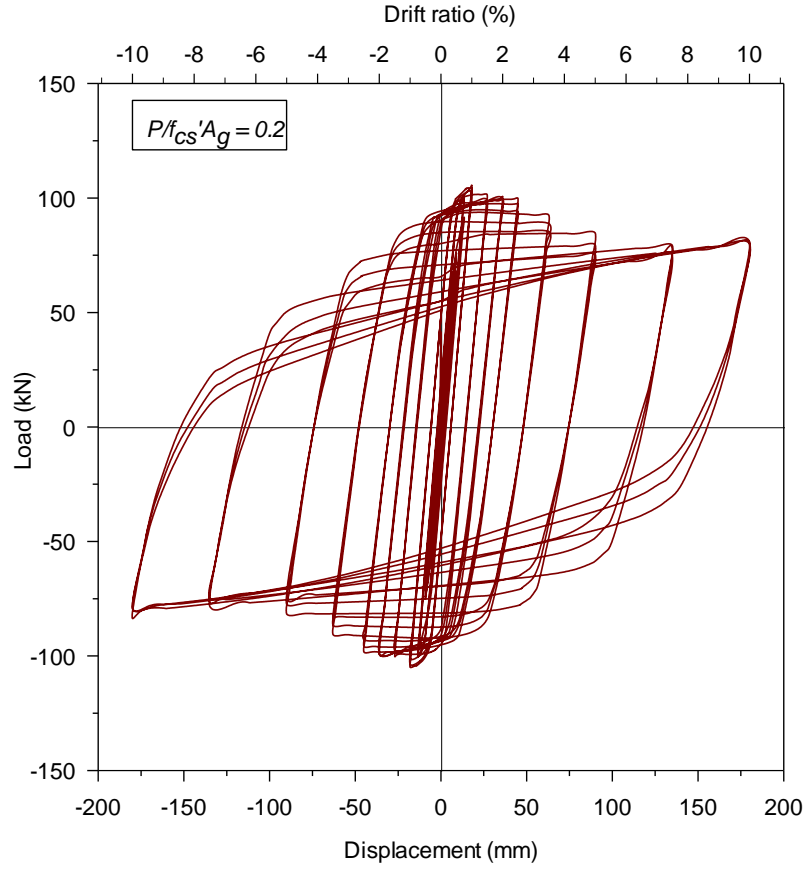

(d) JS4-SFRC2-A20

Figure 11: Load-displacement hysteretic responses of all simulated specimens (continued). 


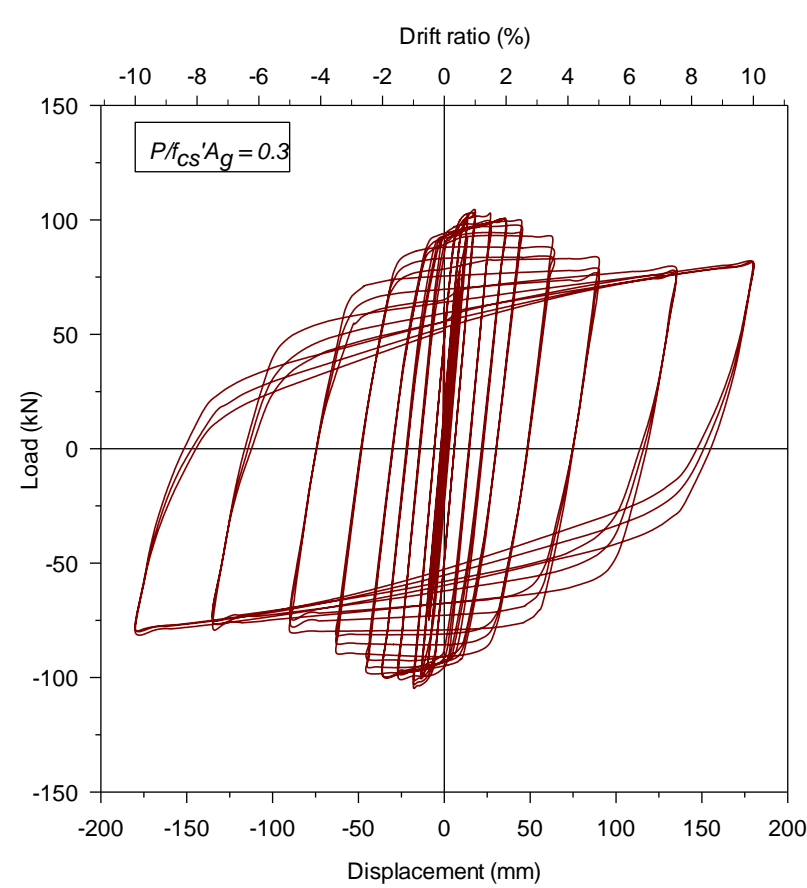

(e) JS4-SFRC2-A30

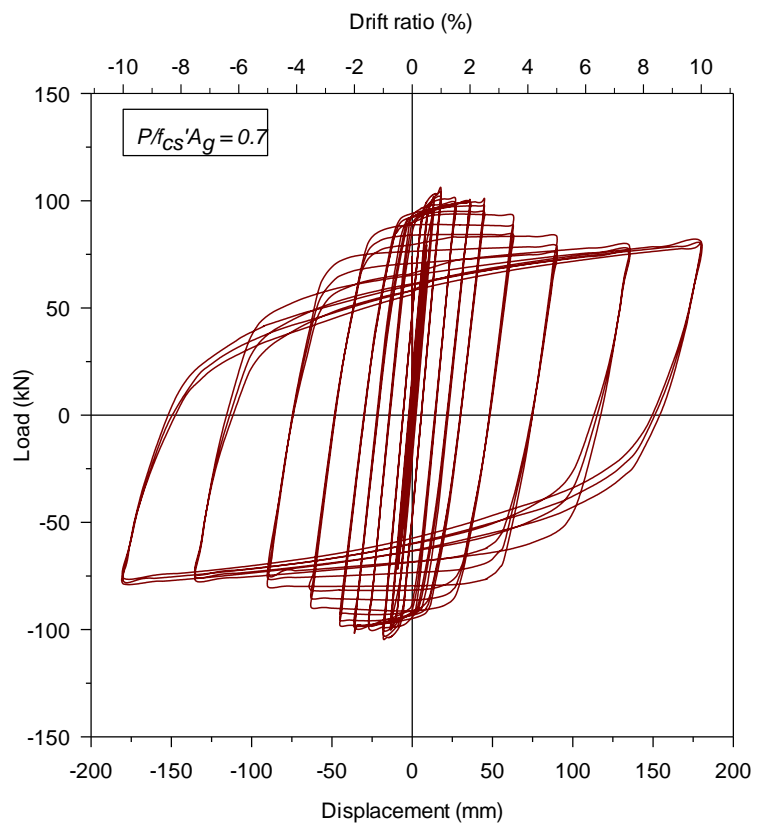

(g) S4-SFRC2-A70

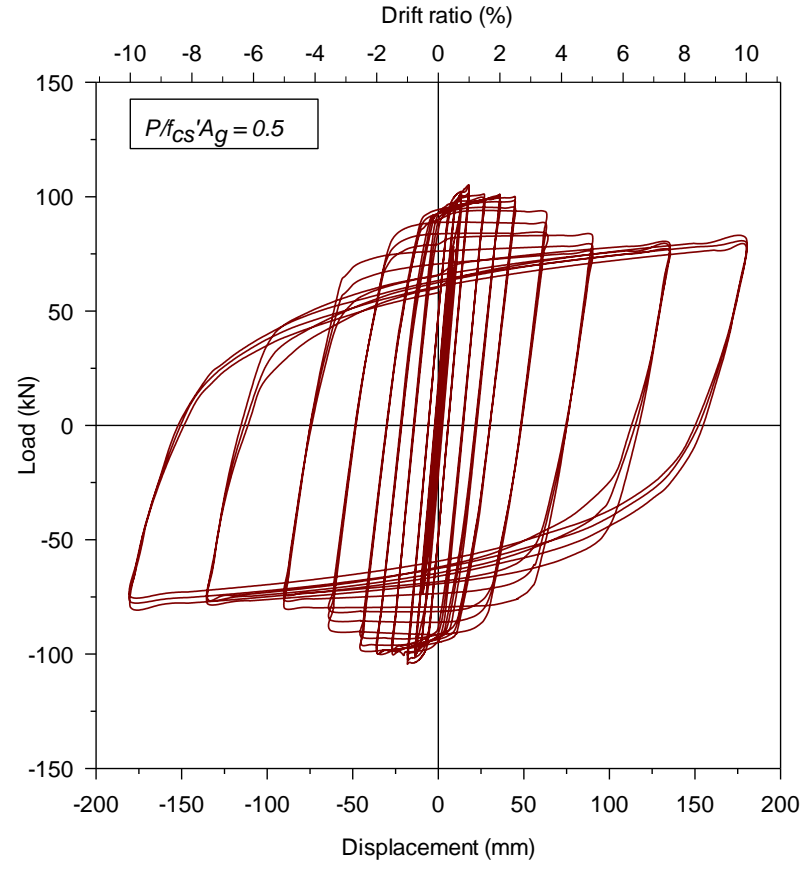

(f) JS4-SFRC2-A50

Drift ratio (\%)

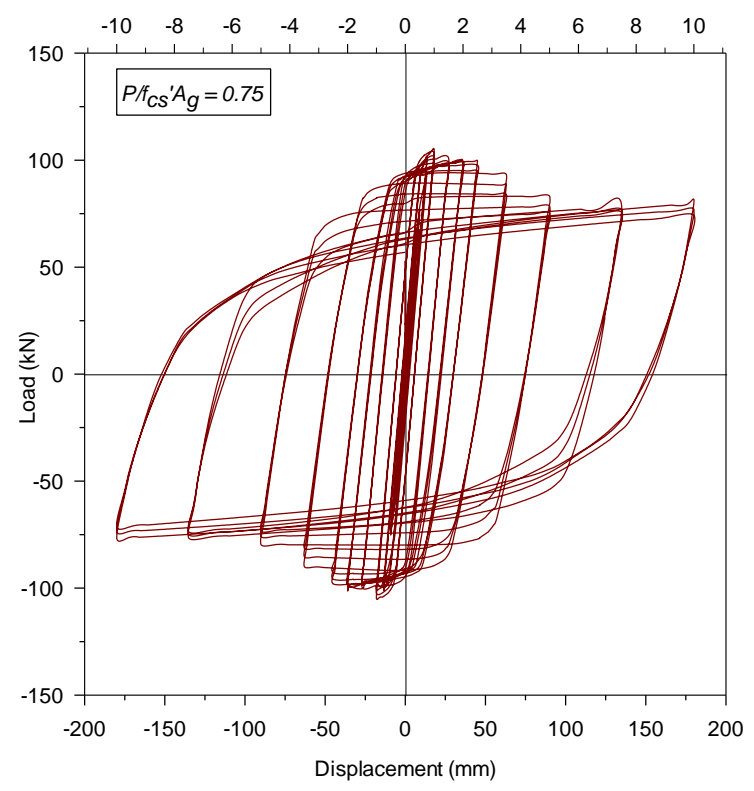

(h) S4-SFRC2-A75

Figure 13: Load-displacement hysteretic responses of all simulated specimens.

The average maximum load-carrying capacity of the specimens under different column axial load levels are exhibited in Fig.12. 


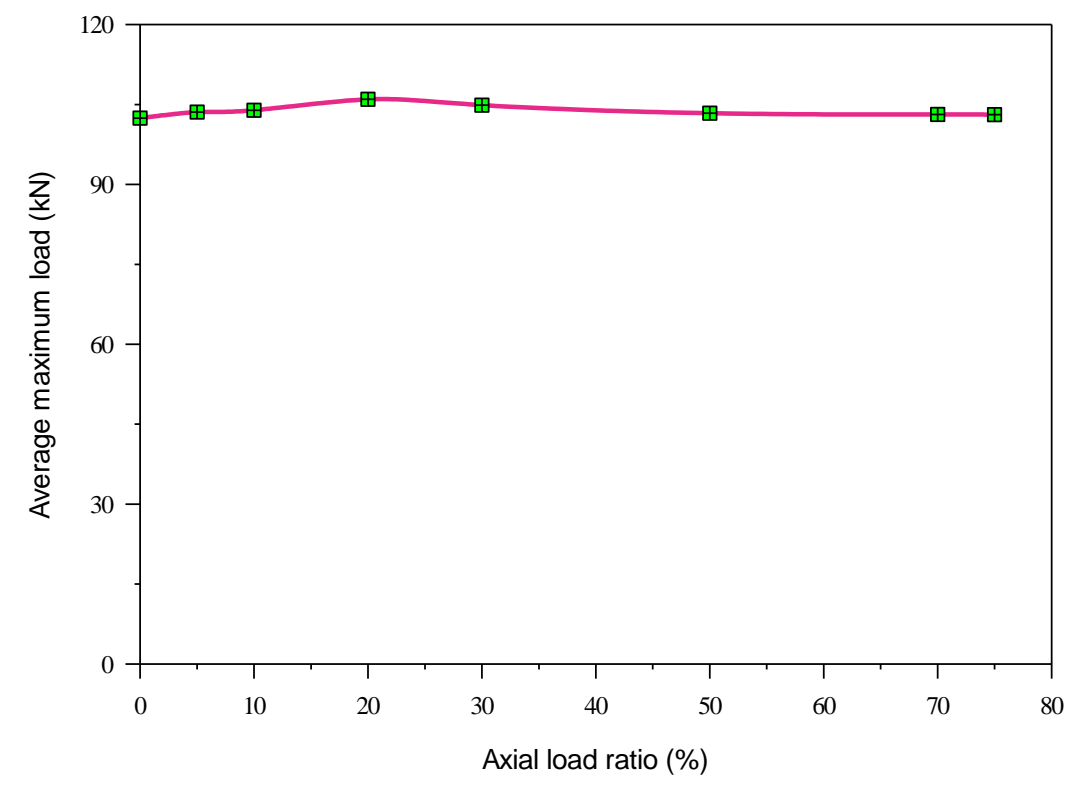

Fig.12: Average maximum load of simulated specimens. (Note: Average value of the maximum load in the push and pull direction are considered).

\subsection{Influence of Column Axial Load Level on Damage and Failure Pattern}

\subsubsection{Joint Cracking Behavior}

Fig.13 to Fig.14 shows the cracking pattern in the joint observed at different stages of loading for specimens with different axial load ratio. The specimens with higher column compressive axial load level were established to delay and reduce the occurrence of cracking in the beam-column joint area in compared to the specimens simulated without column axial load and under low column axial load. Fig.13 illustrates the joint cracks observed in the specimens at the first loading cycle of $1.0 \%$ drift. In specimens under low axial load (JS4-SFRC2-A05 and JS4-SFRC2-A10), the diagonal cracks appeared in this loading stage were very low intensity compared to the specimen without axial load (JS4-SFRC2-A0). However, no joint cracking was observed in the specimens under axial load levels more than $10 \%$ of the column axial capacity $\left(>0.1 f_{c S}^{\prime} A_{g}\right)$. This confirmed that high axial load would delay the formation of joint cracks and it was beneficial for joint confinement.

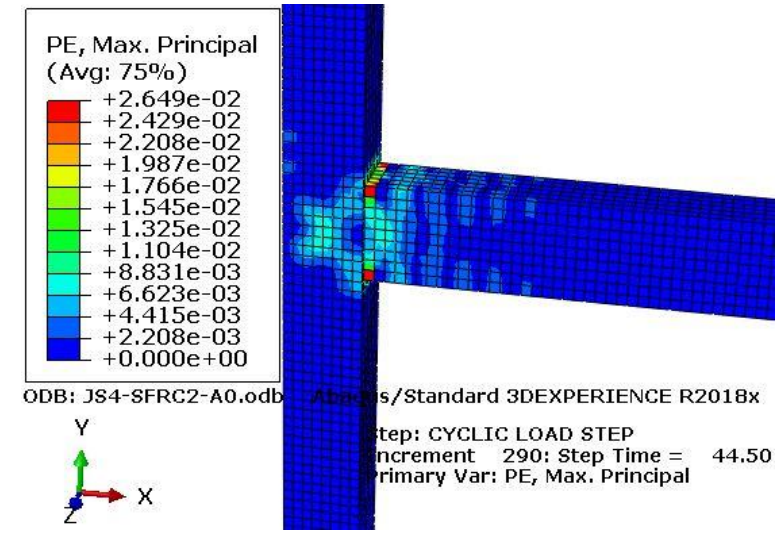

(a). JS4-SFRC2-A0

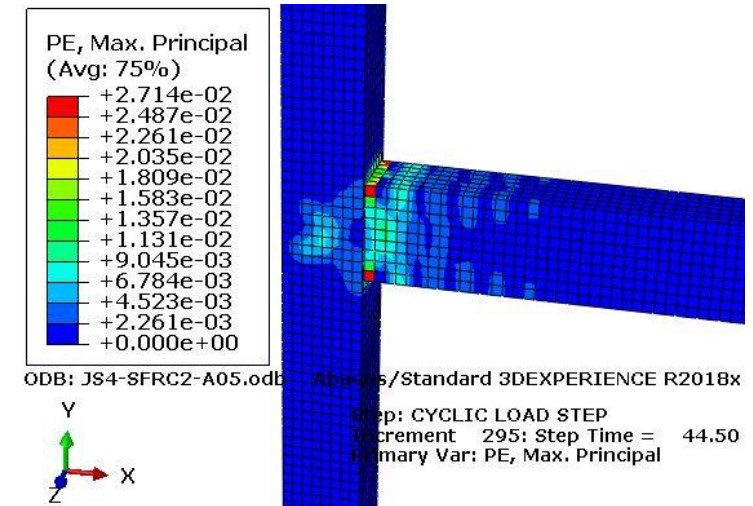

(b). JS4-SFRC2-A05 

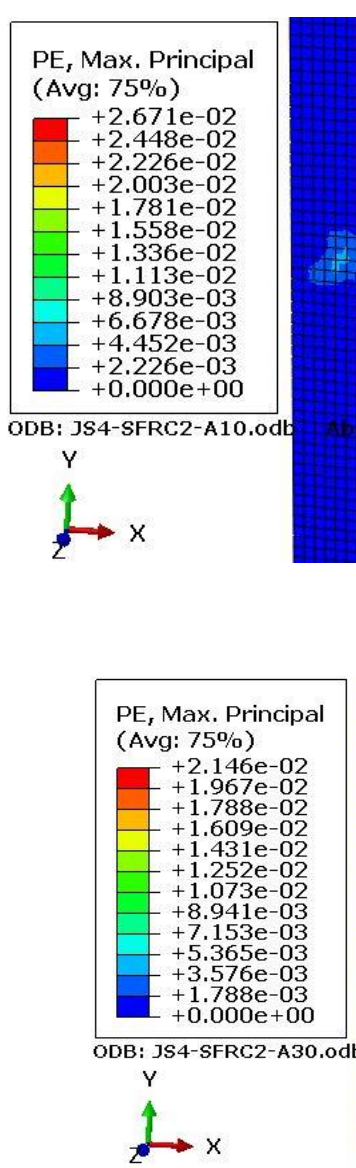

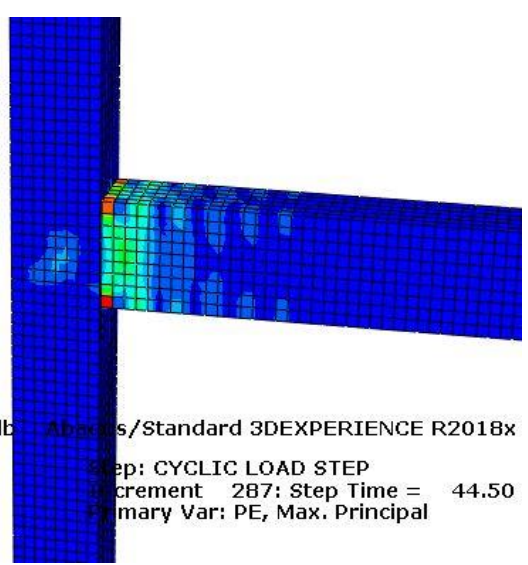

(c) JS4-SFRC2-A10

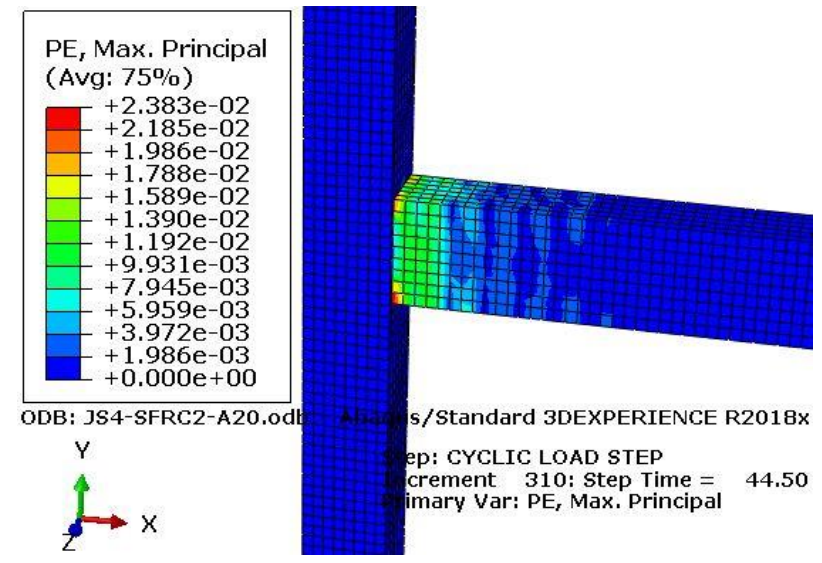

(d). JS4-SFRC2-A20
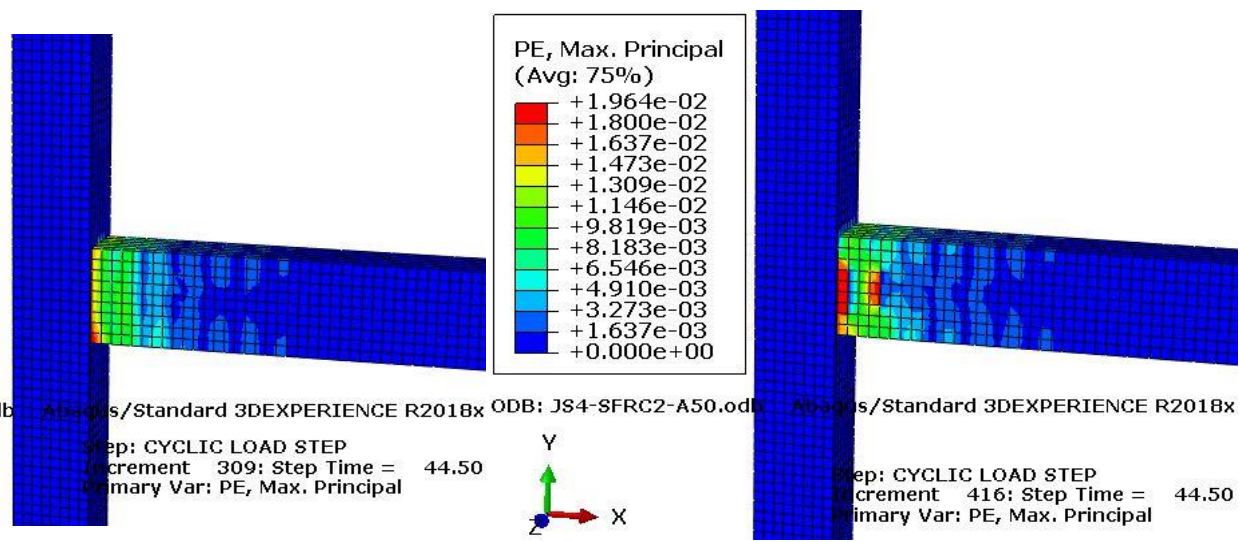

(e) JS4-SFRC2-A30

(f) JS4-SFRC2-A50

Fig.13: Joint cracking behavior of the specimens at $1 \%$ drift ratio (continued).

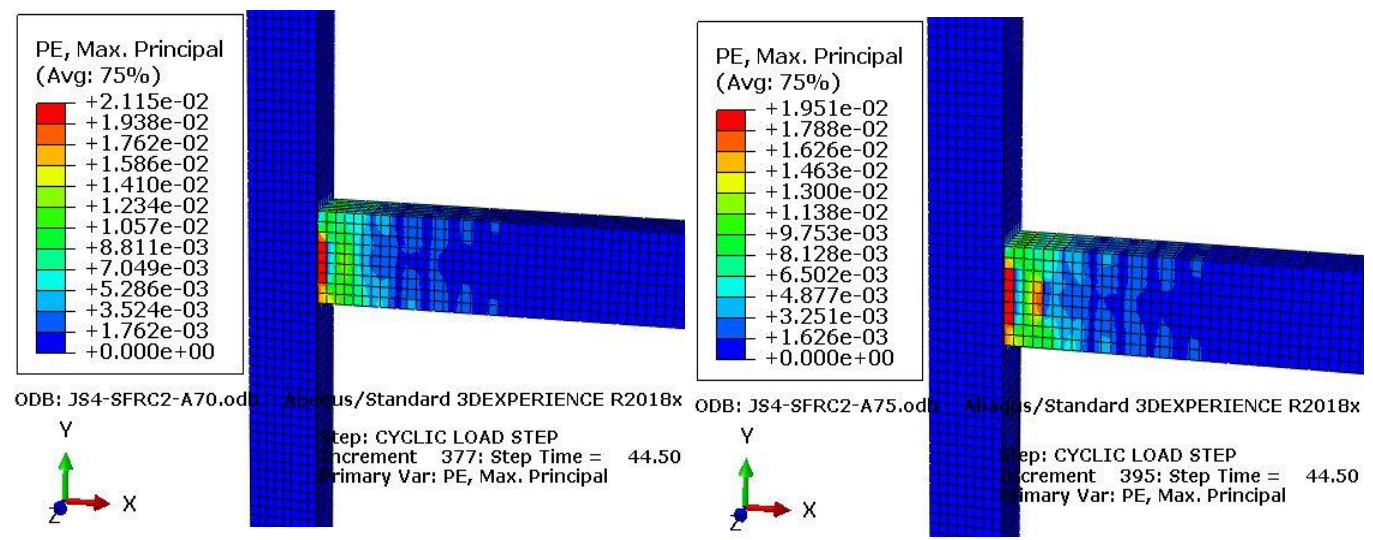

(g) JS4-SFRC2-A70

(h) JS4-SFRC2-A75

Fig.13: Joint cracking behavior of the specimens at $1 \%$ drift ratio.

With further increase of loading cycles, the specimens without axial load (JS4-SFRC2-A0) and under low axial load levels (JS4SFRC2-A05 and JS4-SFRC2-A10) exhibited a significant diagonal shear cracking in the joint core zone and flexural caking in the beam plastic hinge region. However, only flexural cracks observed at the edges of the beam-column junction extended into the beam plastic hinge region for specimens with column axial load level more than $10 \%$ of the column capacity. For example, joint cracking patterns at the first cycle of 5\% drift ratio showed in Fig.14. 


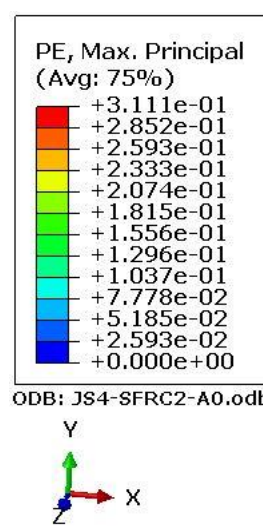

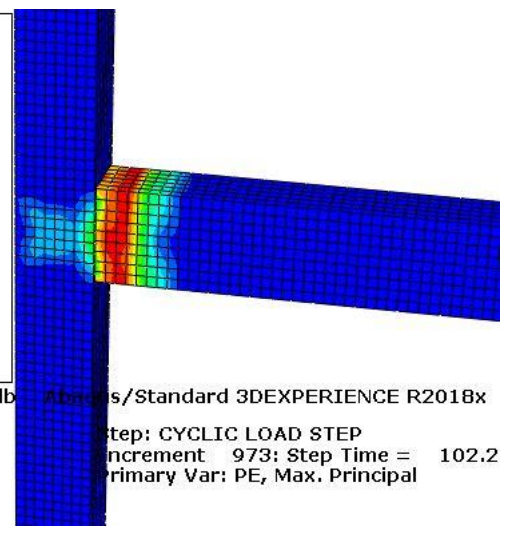

(a) JS4-SFRC2-A0

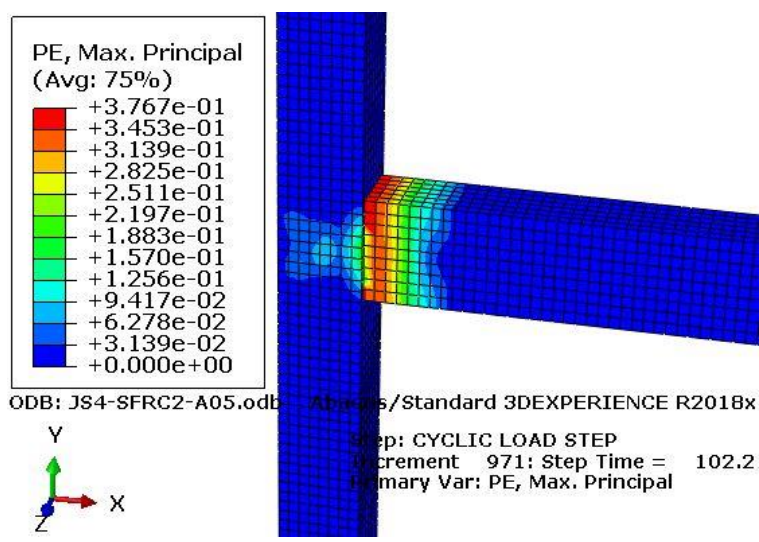

(b) JS4-SFRC2-A05

Fig.14: Joint cracking behavior of all the specimens at 5\% drift ratio (continued).

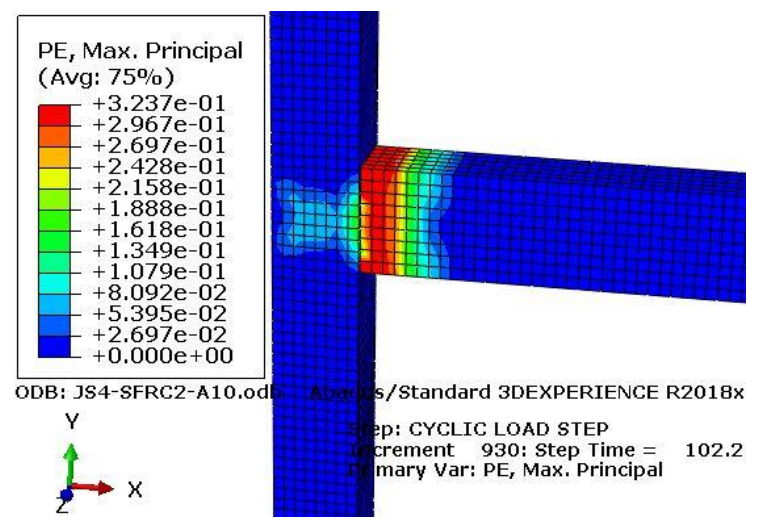

(c) JS4-SFRC2-A10

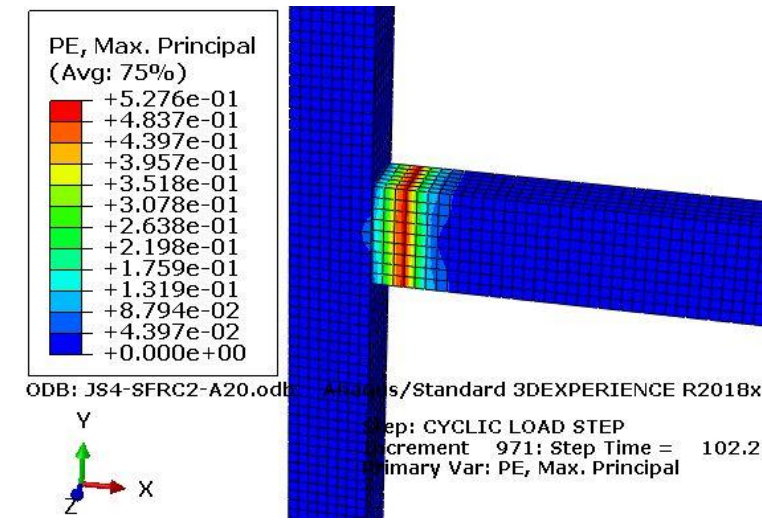

(d) JS4-SFRC2-A20

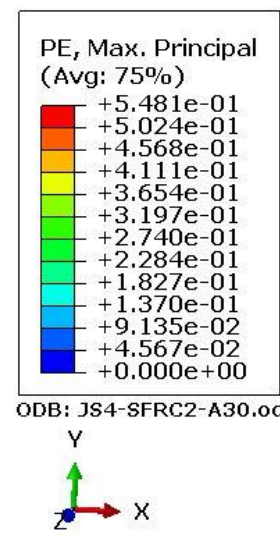

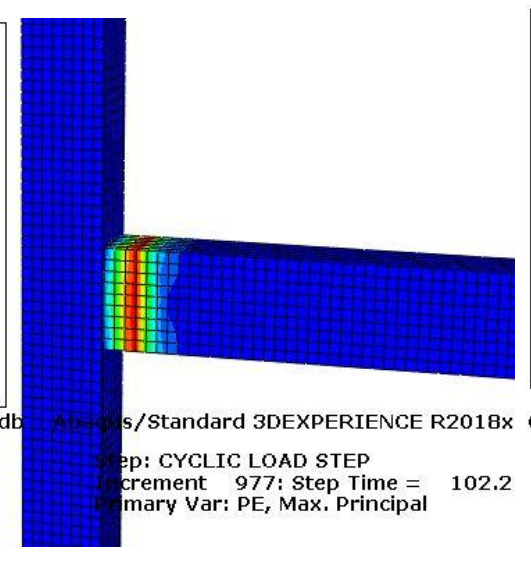

(e) JS4-SFRC2-A30

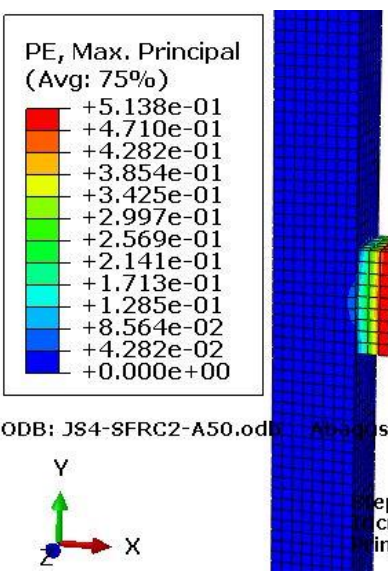

(f) JS4-SFRC2-A50 


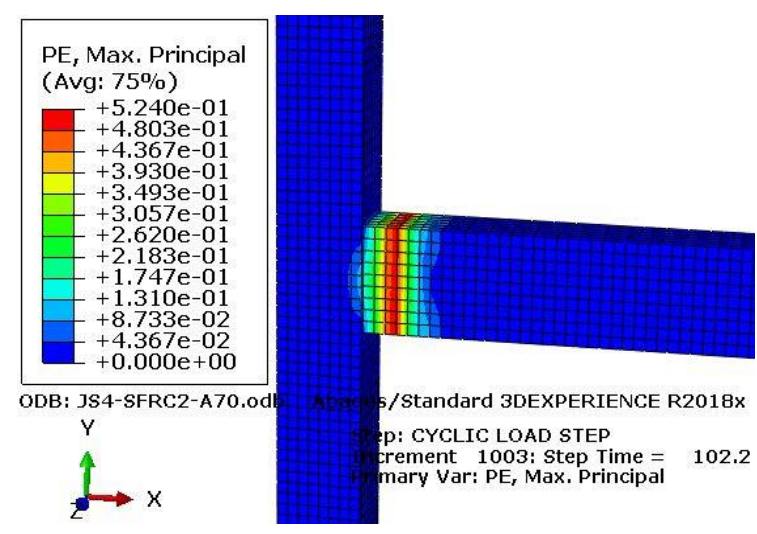

(g) JS4-SFRC2-A70

Fig.14: Joint cracking

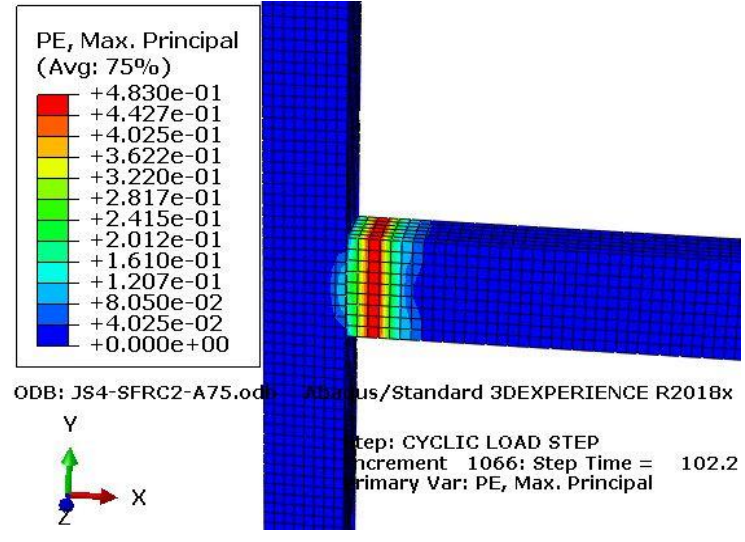

(h) JS4-SFRC2-A75

\subsection{Effects of Column Axial Load on Stiffness Degradation}

Fig. 15 illustrates the peak-to-peak stiffness of all specimens from each first cycle out of three loading cycles at each drift ratio. The specimens with higher axial load ratios were found to have a higher peak-to-peak stiffness than specimens with low axial load ratios in early drift ratios. It was observed that stiffness degradation of specimens had a critical influence only in the initial loading cycles and the stiffness values after a $2.5 \%$ drift ratio of loading were approximately in the same value in specimens with different axial load ratios, but specimens under very high axial load are slightly greater stiffness degradation than specimens with low axial load.

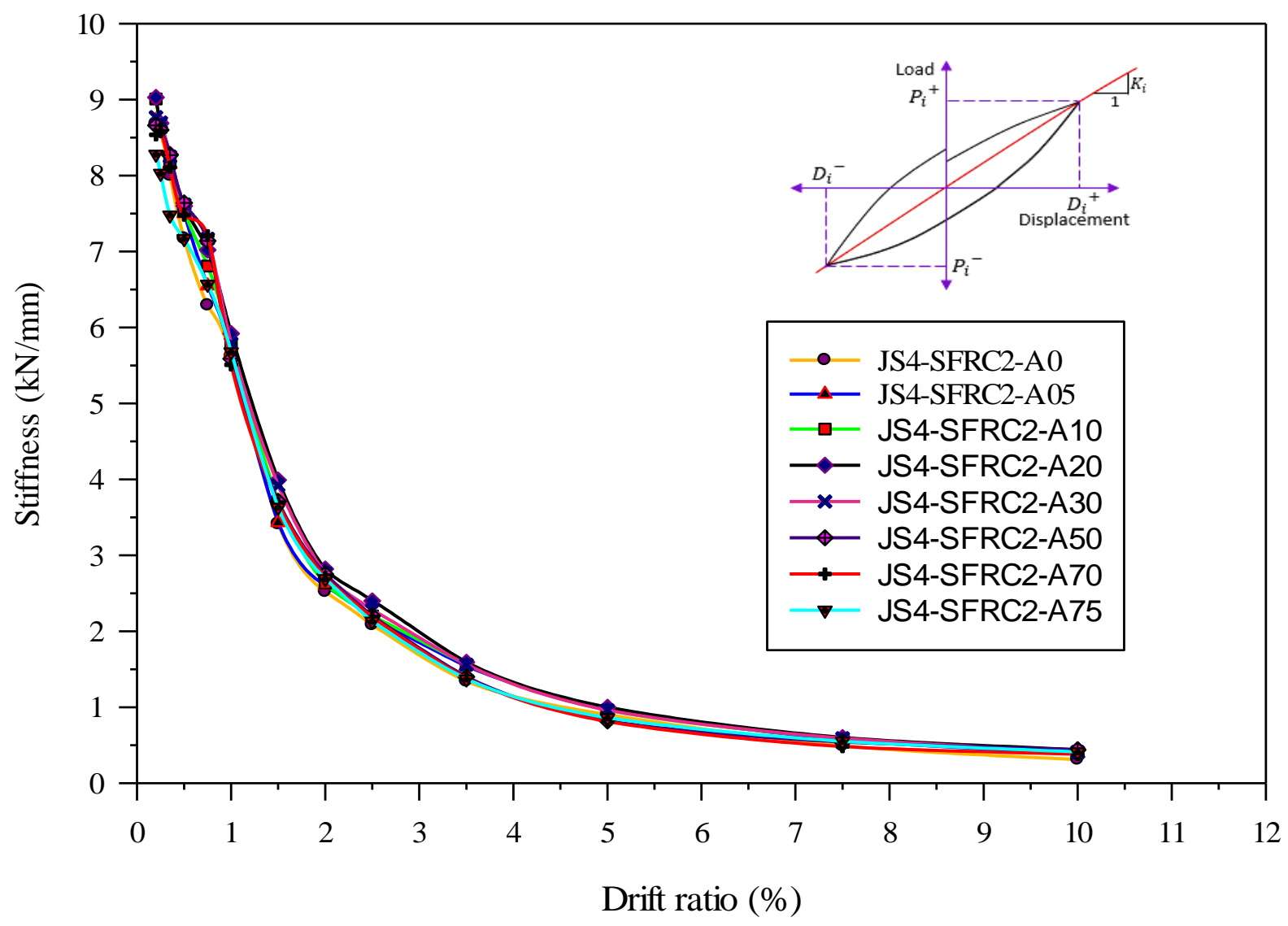

Fig. 15: Stiffness degradation of specimens. 


\subsection{Effects of Column Axial Load on Energy Dissipation Capacity}

The plastic energy dissipation of the specimens is presented in Fig. 16. It can be observed that the specimens with column axial load level up to $0.3 f_{c s}^{\prime} A_{g}$ caused a decrease of the plastic energy dissipation compaired to the specimen without column axial load. However, it was observed that the decreasing rate plastic energy of the specimens with column axial load level more than $0.1 f_{c S}^{\prime} A_{g}$ has greater than compared to the specimen with a column axial load of $0.1 f_{c S}^{\prime} A_{g}$ and less.

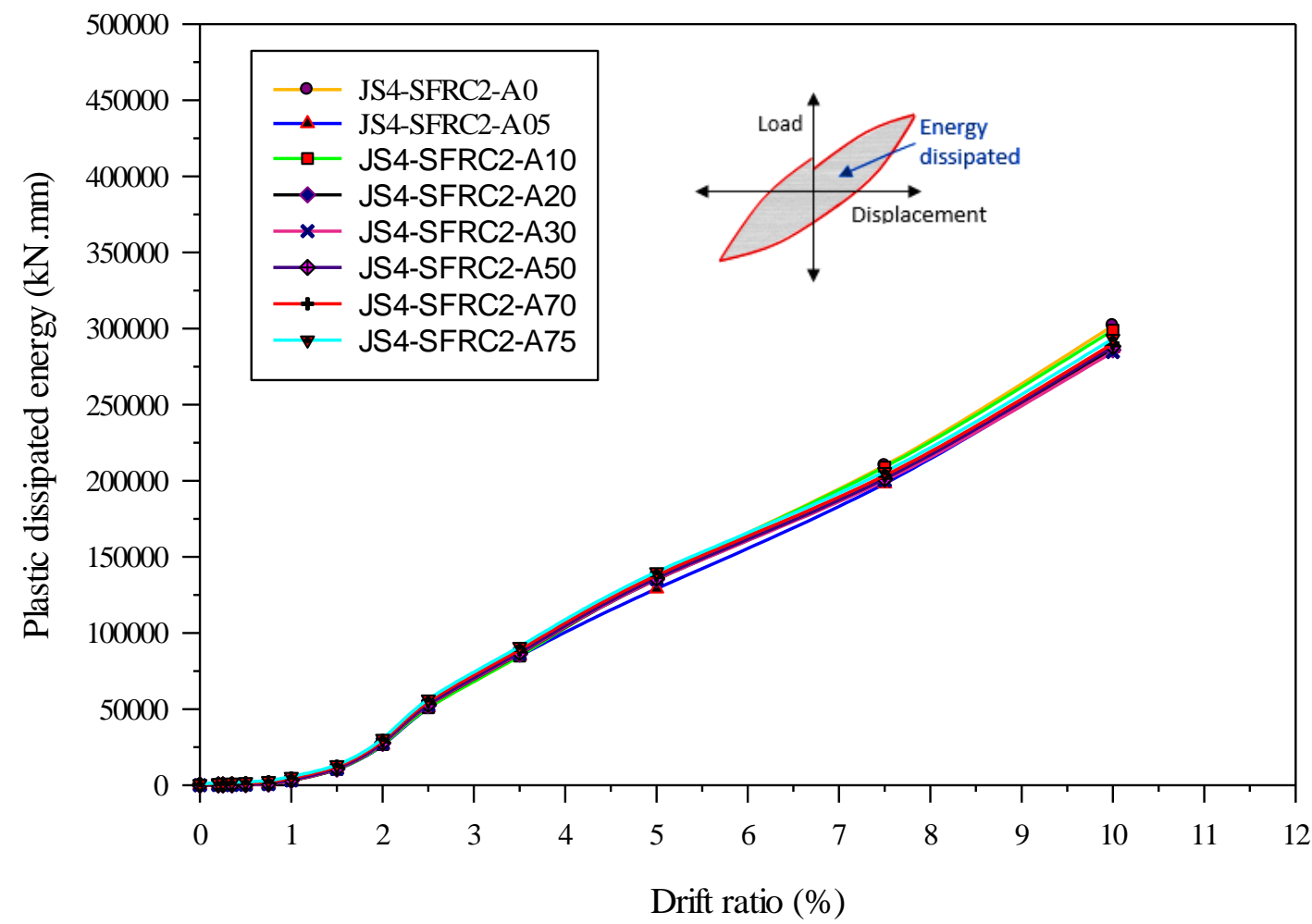

Fig. 16: Plastic energy dissipation of all specimens.

For instance, specimens JS4-SFRC2-A05 and JS4-SFRC2-A10 are dissipating less plastic energy at drift ratios of 7.5\% by only $0.15 \%$ and $0.43 \%$, respectively, compared to the specimen JS4-SFRC2-A0. In addition, specimens JS4-SFRC2-A20, JS4-SFRC2A30, JS4-SFRC2-A50, JS4-SFRC2-A70 and JS4-SFRC2-A75, are displayed less plastic energy at drift ratios of 7.5\% by $4.25 \%$, $4.6 \%, 4.0 \%, 3.0 \%$, and $1.79 \%$, respectively, compared to the specimen JS4-SFRC2-A0. This can be indicated that the increasing of column axial load levels are slightly adverse effect on energy dissipation due to axial failure and local crushing of concrete.

\section{CONCLUSIONS}

Based on the nonlinear finite element analysis results of the simulated beam-column joint specimens to explore the effect of axial load variations on the seismic behavior of steel fiber reinforced concrete exterior beam-column joints, the following conclusions can be drawn:

- The results indicated that an increase of axial load has a valuable influence to delay the initiation of cracks and damage accumulation. Moreover, when the axial load ratio increases up to $50 \%$ of the column capacity, no cracks observed in the joint area, only flexural cracks observed at the beam-column interface and number of cracks in the beam increases with increase of axial load.

- Increasing the column axial load level from 5 to $30 \%$ of the column axial capacity can lead to increase slightly the maximum load-carrying capacity of the beam-column joints. However, increasing of column axial load level more than $30 \%$, no significant change in the maximum load-carrying capacity of the joints compared with no axial load.

- Increasing of column axial load levels enhances the energy dissipation capacity of joints at initial stage of loading, however, slightly adverse effect when the loading stages further increases due to axial failure and local crushing of concrete.

- Increasing the column axial load level resulted slightly improvement of the joint stiffness, this is due to the confining action provided by axial load against joint shear and the development of cross diagonal cracks was suppressed. However, when the axial load level of more than $50 \%$ of the column capacity, the cyclic stiffness decreased slightly due to the deterioration caused by local crushing of concrete in column. Thus, the results indicated that the increase of column axial load improves the confinement of the SFRC beam-column joints, however a threshold limit could be required. 


\section{REFERENCES}

[1] T. Paulay and M. J. N. Priestley, Seismic design of reinforced concrete and masonry buildings. New York: Wiley. 1992

[2] Y. Jiuru, T.; Chaobin, H.; Kaijian, Y.; and Yongcheng, "Seismic Behavior and Shear Strength of Framed Joint Using Steel Fiber Reinforced Concrete," Journal of Structural Engineering, vol. 118, no. 2, pp. 341-358, 1992.

[3] J. Gustavo, Parra-Montesinos, S. Peterfreund, and S. Chao, "Highly damage-tolerant beam-column joints through use of high-performance fiberreinforced cement composites," ACI Structural Journal, vol. 102, no. 3, pp. 487-495, 2005.

[4] N. Ganesan, P. V. Indira, and M. V. Sabeena, "Behaviour of hybrid fibre reinforced concrete beam-column joints under reverse cyclic loads," Materials and Design, vol. 54, pp. 686-693, 2014.

[5] D. Kheni, R. H. Scott, and A. Deb, S. K. and Dutta, "Ductility enhancement in beam-column connections using hybrid fiber-reinforced concrete," ACI Structural Journal, vol. 112, no. 2, pp. 167-178, 2015.

[6] R. . Chidambaram and P. Agarwal, "Seismic behavior of hybrid fiber reinforced cementitious composite beam-column joints," Materials and Design, vol. 86, pp. 771-781, 2015.

[7] M. hossein Saghafi and H. Shariatmadar, "Enhancement of seismic performance of beam-column joint connections using high performance fiber reinforced cementitious composites," Construction and Building Materials, vol. 180, pp. 665-680, 2018.

[8] S. H. Cho and Y. I. Kim, "Effects of Steel Fibers on Short Beams Loaded in Shear," ACI Structural Journal, vol. 100, no. 6, pp. 765-774, 2003.

[9] and J. K. W. Hai H. Dinh, Gustavo J. Parra-Montesinos and Results, "Shear Behavior of Steel Fiber-Reinforced Concrete Beams without Stirrup Reinforcement," vol. 107, no. 5, pp. 597-606, 2010.

[10] P. S. Song and S. Hwang, "Mechanical properties of high-strength steel fiber-reinforced concrete," Construction and Building Materials, vol. 18, no. 9, pp. 669-673, 2004.

[11] A. Thomas, J; Ramaswamy, “Mechanical properties of steel fibre concrete,” Journal of Materials in Civil Engineering, vol. 19 , no. 5, pp. 385-392, 2007.

[12] C. S. Choi andBae.-II, "Effectiveness of steel fibers as hoops in exterior beam-to-column joints under cyclic loading," ACI Structural Journal, vol. 116, no. 2, pp. 205-219, 2019.

[13] P. H. Bischoff, "Tension Stiffening and Cracking of Steel Fiber-Reinforced Concrete," Journal of Materials in Civil Engineeringrials in Civil Engineering, vol. 15, no. 2, pp. 174-182, 2003.

[14] ACI Committee 318, Building Code Requirements for Structural Concrete and Commentary (ACI 318R-08). 2008.

[15] G. Parra-Montesinos, "Shear strength of beams with deformed steel fibers," Concrete International-Detroit-, vol. 28, no. 11, p. 57, 2006.

[16] Li and Leong, "Experimental and Numerical Investigations of the Seismic Behavior of High-Strength Concrete Beam-Column Joints with Column Axial Load," ASCE Journal of Structural Engineering, 2014.

[17] Simulia, “ABAQUS Version 2018: Dassault Systemes Simulia Corp: 2017.” 2017.

[18] M. A. Najafgholipour, S. M. Dehghan, A. Dooshabi, and A. Niroomandi, "Finite element analysis of reinforced concrete beam-column connections with governing joint shear failure mode," Latin American Journal of Solids and Structures, vol. 14, no. 7, pp. 1200-1225, 2017.

[19] H. Behnam, J. S. Kuang, and B. Samali, "Parametric finite element analysis of RC wide beam-column connections," Computers and Structures, vol. 205, pp. 28-44, 2018.

[20] ACI Committee 374, "Guide for testing reinforced concrete structural elements under slowly applied simulated seismic loads (ACI 374.2R-13)," American Concrete Institute, Farmington Hills, MI, p. 22, 2013.

[21] J. G. Stoner, "Finite element modelling of GFRP reinforced concrete beams," 2015.

[22] J. Lubliner, J. Oliver, S. Oller, and E. Onate, “A Plastic-Damage Model for Concrete," International Journal of Solids and Structures, vol. 25, no. 3, pp. 299-326, 1989

[23] J. Lee and G. L. Fenves, "Plastic-damage model for cyclic loading of concrete structures," Journal of Engineering Mechanics, vol. 124, no. 8, pp. 892900,1998

[24] ACI Committee 544, “Design Considerations for Steel Fiber Reinforced Concrete,” ACI Structural Journal, vol. 88, no. Reapproved 1999, 1988.

[25] ACI Committee 544.1R-96, "State-of-the-Art Report on Fiber Reinforced Concrete. (ACI 544.1R-96)," C American Concrete Institute, Farmington Hills, $M I$, p. 66, 2002.

[26] P. Ezeldin, A. and Balagurur, "Normal- and h i g h - s t r e $\mathrm{n}$ g t h fiber-reinforced concrete under compression," Journal of Materials in Civil Engineering, vol. 4, no. 4, pp. 415-429, 1992.

[27] J. Barros, J.A.O. \& Figueiras, "Flexural Behaviour of Steel Fibre Reinforced Concrete: Testing and Modelling," Journal of Materials in Civil Engineering, vol. 11 , no. 4 , pp. 331-339, 1999.

[28] M. C. Nataraja, N. Dhang, and A. P. Gupta, "Stress-Strain Curve for Steel Fibre Reinforced Concrete Under Compression," Cement and Concrete Composites, vol. 21, pp. 383-390, 1999.

[29] D. Dupont, "Modelling and experimental validation of the constitutive law and cracking behavior of Steel Fiber Reinforced Concrete," Heverlee, Catholic Universty of Leuven, 2003.

[30] R. N. Bencardino, F., Rizzuti, L., Spadea, G. \& Swamy, "Stress-strain behavior of steel fiber-reinforced concrete in compression," ASCE Journal of Materials in Civil Engineering, vol. 20, no. 3, pp. 255-263, 2008.

[31] J. H. Lee, S.C., Oh and J. Y. Cho, "Compressive behavior of fiber-reinforced concrete with end-hooked steel fibers," Materials, vol. 8, no. 4, pp. 1442$1458,2015$.

[32] ACI Committee 544.3R-93, "Guide for Specifying, Proportioning, Mixing, Placing, and Finishing Steel Fiber Reinforced Concrete (ACI 544.3R-93)," American Concrete Institute, Farmington Hills, MI, p. 10, 1998.

[33] K. C. Ou, Y.C., Tsai, M.S., Liu, K.Y., Chang, "Compressive Behavior of Steel-Fiber-Reinforced Concrete with a High Reinforcing Index," Journal of Materials in Civil Engineering, vol. 24, no. 2, pp. 207-215, 2012.

[34] C. Wang, "Eperimental Investigation of the Behavior of Steel Fiber Reinforced Concrete," Masters Thesis, University of Canterbury, p.165, 2006.

[35] J. A. O. Barros and J. A. Figueiras, "Model for the analysis of steel fibre reinforced concrete slabs on grade," Computers and Structures, vol. 79, no. 1, pp. 97-106, 2001.

[36] T. S. Lok and J. R. Xiao, "Flexural strength assessment of steel fiber-reinforced concrete," Journal of Materials in Civil Engineering, vol. 11, no. 3, pp. $188-196,1999$.

[37] H. Tlemat, K. Pilakoutas, and K. Neocleous, "Modelling of SFRC using inverse finite element analysis," RILEM Materials and Structures, vol. 39, no. 286, pp. 221-233, 2006.

[38] S. M. B. S. Mohsin, "Behaviour Of Fibre-Reinforced Concrete Structures Under Seismic Loading," Department of Civil and Environmental Engineering Imperial College London, no. April, p. 340, 2012.

[39] A. Abbas and S. S. Mohsin, "Numerical modeling of fibre-reinforced concrete," no. 2006, pp. 2005-2006, 2010.

[40] T. S. Lok and J. R. Xiao, "Tensile behaviour and moment-curvature relationship of steel fibre reinforced concrete," Magazine of Concrete Research, vol. 50, no. 4, pp. 359-368, 1998.

[41] D. J. Hannant, Fibre cements and fibre concretes. 1979.

[42] P. Soroushian and C. D. Lee, "Distribution and orientation of fibers in steel fiber reinforced concrete," ACI Materials Journal, vol. 87, no. 5, pp. 433439,1990 
[43] A. Amin and R. I. Gilbert, "Steel fiber-reinforced concrete beams-Part I: Material characterization and in-service behavior," ACI Structural Journal, vol. 116, no. 2, pp. 101-111, 2019.

[44] T. Y. Lim, P. Paramasivam, and S. L. Lee, “Analytical Model for Tensile Behavior of Steel-Fiber Concrete,” ACI Materials Journal, vol. 84, no. 4, pp. 286-298, 1987.

[45] B. W. Xu and H. S. Shi, "Correlations among mechanical properties of steel fiber reinforced concrete," Construction and Building Materials, vol. 23, pp. 3468-3474, 2009.

[46] Eurocode 2, "Design of Concrete Structures: Part 1-1: General Rules and Rules for Buildings," CEN, London, 2004.

[47] T. Kachlakev, D. I.; Miller, "Finite Element Modeling of Reinforced Concrete Structures Strengthened with FRP Laminates," Oregon Department of Transportation Research Group \& Federal Highway Administration, Washington, DC, USA, p. 113, 2001.

[48] A. M. A. Ibrahim, M. F. M. Fahmy, and Z. Wu, "3D finite element modeling of bond-controlled behavior of steel and basalt FRP-reinforced concrete square bridge columns under lateral loading," Composite Structures, vol. 143, pp. 33-52, 2016.

[49] A. Raza, Q. U. Z. Khan, and A. Ahmad, "Numerical investigation of load-carrying capacity of GFRP-reinforced rectangular concrete members using CDP model in abaqus," Advances in Civil Engineering, vol. 2019, 2019.

[50] ACI-ASCE Committee 352, "Recommendations for Design of Beam-Column Joints in Monolithic Reinforced Concrete Structures (ACI 352R-02)," American Concrete Institute, Farmington Hills, MI, p. 37, 2002.

[51] ACI Committee 318, "Building Code Requirements for Structural Concrete (ACI 318-14) and Commentary (ACI 318R-14)," American Concrete Institute, Farmington Hills, MI, p. 520, 2014.

[52] A. R. Mohamed, M. S. Shoukry, and J. M. Saeed, "Prediction of the behavior of reinforced concrete deep beams with web openings using the finite ele ment method," Alexandria Engineering Journal, vol. 53, no. 2, pp. 329-339, 2014.

[53] V. G. Haach, A. Lúcia Homce De Cresce El Debs, and M. Khalil El Debs, "Evaluation of the influence of the column axial load on the behavior of monotonically loaded R/C exterior beam-column joints through numerical simulations,” Engineering Structures, vol. 30, no. 4, pp. 965-975, 2008. 